\title{
MEASURING RICE YIELD FROM SPACE: THE CASE OF THAI BINH PROVINCE, VIET NAM
}

Kaiyu Guan, Ngo The Hien, Zhan Li, and Lakshman Nagraj Rao

NO. 541

March 2018
ADB ECONOMICS WORKING PAPER SERIES 
ADB Economics Working Paper Series

\section{Measuring Rice Yield from Space: The Case of Thai Binh Province, Viet Nam}

Kaiyu Guan, Ngo The Hien, Zhan Li, and Lakshman Nagraj Rao

No. 541 | March 2018
Kaiyu Guan (kaiyug@illinois.edu) is an Assistant Professor at the Department of Natural Resources and Environmental Sciences and Blue Waters professor at the National Center for Supercomputing Applications, University of Illinois at Urbana Champaign. Ngo The Hien (hiennt@mard.gov.vn) is the Director General of the Centre for Informatics and Statistics, Ministry of Agriculture and Rural Development in Viet Nam. Zhan Li (zhan.li@umb.edu) is a Research Fellow at the School for the Environment, University of Massachusetts Boston. Lakshman Nagraj Rao (NagrajRao@adb.org) is a Statistician at the Economics Research and Regional Cooperation Department, Asian Development Bank.

This study was carried out under Regional Technical Assistance (R-CDTA) 8369: Innovative Data Collection Methods for Agricultural and Rural Statistics with the support of the Japan Fund for Poverty Reduction (JFPR). The authors benefited from the insightful comments of Yasuyuki Sawada, Rana Hasan, Jesus Felipe, Kaushal Joshi, Valerie Mercer-Blackman, Mahinthan Joseph Mariasingham, David Anthony Raitzer, Tadayoshi Yahata, and Pamela Lapitan. The authors are also grateful to the Ministry of Agriculture and Rural Development (Viet $\mathrm{Nam}$ ) and the Japan Aerospace Exploration Agency for providing the data used in this study. Anna Christine Durante, Lea Rotairo, Rea Jean Tabaco, and Chrysalyn Gocatek provided excellent research assistance. 
(C) 2018 Asian Development Bank

6 ADB Avenue, Mandaluyong City, 1550 Metro Manila, Philippines

Tel +632632 4444; Fax +6326362444

www.adb.org

Some rights reserved. Published in 2018.

ISSN 2313-6537 (print), 2313-6545 (electronic)

Publication Stock No. WPS189283-2

DOI: http://dx.doi.org/10.22617/WPS189283-2

The views expressed in this publication are those of the authors and do not necessarily reflect the views and policies of the Asian Development Bank (ADB) or its Board of Governors or the governments they represent.

ADB does not guarantee the accuracy of the data included in this publication and accepts no responsibility for any consequence of their use. The mention of specific companies or products of manufacturers does not imply that they are endorsed or recommended by ADB in preference to others of a similar nature that are not mentioned.

By making any designation of or reference to a particular territory or geographic area, or by using the term "country" in this document, $A D B$ does not intend to make any judgments as to the legal or other status of any territory or area.

This work is available under the Creative Commons Attribution 3.0 IGO license (CC BY 3.0 IGO)

https://creativecommons.org/licenses/by/3.0/igo/. By using the content of this publication, you agree to be bound by the terms of this license. For attribution, translations, adaptations, and permissions, please read the provisions and terms of use at https://www.adb.org/terms-use\#openaccess.

This CC license does not apply to non-ADB copyright materials in this publication. If the material is attributed to another source, please contact the copyright owner or publisher of that source for permission to reproduce it. $\mathrm{ADB}$ cannot be held liable for any claims that arise as a result of your use of the material.

Please contact pubsmarketing@adb.org if you have questions or comments with respect to content, or if you wish to obtain copyright permission for your intended use that does not fall within these terms, or for permission to use the ADB logo.

Notes:

In this publication, "\$” refers to US dollars.

Corrigenda to ADB publications may be found at http://www.adb.org/publications/corrigenda. 


\section{CONTENTS}

TABLES AND FIGURES

ABSTRACT

$\begin{array}{ll}\text { I. INTRODUCTION } & 1\end{array}$

II. DATA AND METHODOLOGY 4

A. Study Area $\quad 4$

B. Landsat-MODIS Fusion 5

C. ALOS-2/PALSAR-2 Data 6

D. Paddy Rice Mapping and Land Cover Classification 7

E. Crop Yield Estimation $\quad 8$

III. RESULTS $\quad 12$

A. Landsat-MODIS Fusion $\quad 12$

B. Paddy Rice Mapping 13

$\begin{array}{ll}\text { C. Crop Yield Estimation } & 14\end{array}$

$\begin{array}{lll}\text { IV. CONCLUSION } & 18\end{array}$

$\begin{array}{ll}\text { APPENDIX } & 21\end{array}$

BIBLIOGRAPHY 23 


\section{TABLES AND FIGURES}

\section{TABLES}

$1 \quad$ Landsat Scenes Used in the Landsat-MODIS Fusion 5

2 Satellite Data Information in the Study Area 6

3 Classification Scheme $\quad 7$

$4 \quad$ List of Input Datasets for Land Cover Classification 8

5 Distribution of Sample Meshes by Stratum for the Crop Cutting Survey 9 in Thai Binh, Viet Nam

A.1 Estimated Error Matrix for the Classification Using Landsat + ALOS-2 21

A.2 Estimated Error Matrix for the Classification Using Landsat 21

A.3 Estimated Error Matrix for the Classification Using Fusion Normalized Difference 21 Vegetation Index Savitzky-Golay Fit

A.4 Estimated Error Matrix for the Classification Using ALOS-2 22

A.5 Estimated Error Matrix for the Merged Classification 22

\section{FIGURES}

$1 \quad$ Growth Cycle of Paddy Rice: A Conceptual Framework to Model Crop Yield 4

2 Examples of How Peak Values of Normalized Difference Vegetation Index 11 were Derived from the Landsat-MODIS Fusion Data

$3 \quad$ Normalized Difference Vegetation Index Time Series 12

$4 \quad$ Results from Using Four Different Inputs 13

$5 \quad$ Classified Land Cover Map Resulting from Merging Four Inputs 14

$6 \quad$ Linear Regression Model between the Peak of Vegetation Indexes and Crop Yield 15

$7 \quad$ Scatterplots between ALOS-2 and Crop Cutting Yield Data 16

$8 \quad$ Spatially Explicit Yield Map Based on Normalized Difference Vegetation Index 17

9 Probability Density Histogram of Satellite-Based and Spatially Explicit Crop Yield 18

Estimates over Thai Binh Province 


\begin{abstract}
Despite a growing interest in using satellite data to estimate paddy rice yield in Southeast Asia, significant cloud coverage has led to a scarcity of usable optical data for such analysis. In this paper, we study the feasibility of using two alternative sources of satellite data-(i) surface reflectance fusion data which integrates Landsat and Moderate Resolution Imaging Spectroradiometer (MODIS) images, and (ii) L-band radar backscatter data from the Advanced Land Observing Satellite 2 (ALOS-2) PALSAR-2 sensors - to circumvent the cloud cover problem and estimate yield in Thai Binh Province, Viet Nam during the second growing season of 2015. Our findings indicate that although LandsatMODIS fusion data are not necessarily beneficial for paddy rice mapping when compared with only using Landsat data, fusion data allows us to estimate the peak value of various vegetation indexes and derive the best empirical relationship between these indexes and yield data from the field. We also find that the L-band radar data not only has a lower performance in paddy rice mapping when compared with optical data, but also contributes little to rice yield estimation.
\end{abstract}

Key words: agriculture, ALOS-2, crop cutting, crop yield, Fusion, Landsat, MODIS, paddy rice, remote sensing, Viet Nam

JEL codes: $\mathrm{C} 40, \mathrm{O} 13, \mathrm{Q} 18$ 


\section{INTRODUCTION}

Rice is an important staple crop grown in Southeast Asia, accounting for nearly 25\% of the total rice area planted in the world and more than $22 \%$ of global rice production (FAO 2016). Roughly $26 \%$ of the total consumption expenditure on food and beverages is allocated to rice for households in the poorest quartile of the population in Southeast Asia (World Bank 2016). Timely and reliable rice production estimates are therefore important in designing and monitoring government development plans related to food security in the region.

Traditionally, crop area and yield are estimated using administrative data, whereby government agricultural extension officers observe harvests, interview village heads and/or farmers in their assigned localities, and report the estimates to their next level of bureaucracy, until the summary statistics reach the national government. While this data collection approach is inexpensive, estimates derived can be prone to large measurement errors (ADB 2016). Data collection officers and others involved in the process tend to overestimate production in their assigned areas to support their claims of accomplishment (Carfagna and Carfagna 2010). Administrative reporting often does not usually include a validation process that could improve the quality of estimates (ADB 2016).

If objectively designed and conducted, farmer recall or crop cutting surveys can provide better estimates from crop area and yield than administrative data (ADB 2016). However, methodological studies suggest that during interviews, farmers may inadvertently provide inaccurate crop area and production estimates (Dillon et al. 2017, Desiere and Jolliffe 2017, ADB 2016). Moreover, household surveys are expensive and countries may opt to conduct annual production surveys instead of generating quarterly estimates, leading to recall-based measurement error (De Groote and Traoré 2005). Finally, because household surveys take longer to implement, process, and analyze, their results do not reach policy makers in time for planning the next cropping season.

An alternative to using administrative data or conducting surveys is the application of satellite remote sensing techniques, which has been ongoing for the past several decades with some progress achieved for paddy rice (Kuenzer and Knauer 2013; Mosleh, Hassan, and Chowdhury 2015). There are usually three major applications of satellite data with respect to paddy rice: (i) identifying rice-planted areas, (ii) monitoring in-season crop growth condition and progress, and (iii) estimating or forecasting end-of-season crop yield. Given that majority of paddy rice growing in tropical monsoon areas of Southeast Asia is interspersed over long and multiple rainy seasons, continuous cloudy coverage over an extended period is common. This poses a big challenge in using optical sensors for crop monitoring. This is also why microwave sensors have long been used for paddy rice applications since they can penetrate clouds and are weather independent (Inoue et al. 2002). It is worth noting that depending on the wavelength or frequency of sensors, microwave signals can have different interactions with landscape, making the interpretation of their backscatter complex and prone to significant measurement errors (Inoue et al. 2002; Mosleh, Hassan, and Chowdhury 2015).

From a methodological perspective, substantial progress has been made on remote sensing techniques to identify rice areas. Dong and Xiao (2016) provide a thorough review of the evolution of satellite-based mapping algorithm for paddy rice. Among various existing approaches, using temporal information of seasonal progression from either optical or microwave data is the most advanced approach (Dong and Xiao 2016). For example, the unique features of optical sensors have been found

\footnotetext{
Optical sensors are those that include visible, near-infrared, and short-wave infrared bands, and cannot penetrate through
} clouds. 
to be effective for distinguishing paddy rice from other types of vegetation and land cover (Xiao et al. 2005 and 2006). However, leveraging such features require continuous time series of satellite images covering the same region. This limits the potential uses of this approach for both optical and microwave data. Continuous time series data from optical satellite sensors are also usually available at medium-to-coarse resolution (e.g., Moderate Resolution Imaging Spectroradiometer [MODIS]) (Wardlow and Egbert 2008, Xiao et al. 2006), but fine-spatial-resolution data such as Landsat and other commercial satellite data usually do not have enough clear-day scenes due to low temporal sampling frequency and presence of clouds in tropical regions (Whitcraft, Becker-Reshef, and Justice 2015). This means that mapping of paddy rice using the temporal features can only be achieved at medium-to-coarse resolution, leading to the unfulfilled needs of finer-spatial-resolution map for smallholder rice fields. Cost is another important consideration while selecting the optimal satellite data source. Given that all data sources that can provide time series information for microwave sensors (except Sentinel-1) are not free of charge, there is an inherent limitation on the applicability of radar data for large-scale paddy rice mapping. Monitoring in-season crop growth progress using satellite data essentially shares the similar challenges as the mapping of paddy rice fields discussed above, as it also requires time series information; and ideally, a long-term historical record is required for benchmarking and calculating the deviation from the long-term mean. This is why the state-of-the-art monitoring systems for paddy rice (e.g., GEO Global Agricultural Monitoring Initiative [GeoGLAM], Asia Rice Crop Estimation and Monitoring [Asia-RiCE]) primarily rely on MODIS data (Whitcraft, BeckerReshef, and Justice 2015).

Estimating rice production not only requires information on area planted, but also calculating yield, which in the remote sensing context is still at a very nascent stage. There are several major challenges associated with satellite-based crop yield estimation. Firstly, there is a lack of reliable ground-truth crop yield data for model calibration and testing at regional scales. Field-level crop cutting data is usually costly and labor intensive, and district-level crop statistics are either not easily accessible or of low quality in developing countries (ADB 2016). Secondly, satellite data with both high temporal and spatial resolutions is limited in terms of availability and cost. Given that the majority of paddy rice fields in Southeast Asia are smallholder farms, there is a need for high spatial resolution data down to 10-30 meters $(\mathrm{m})$, and high-frequency time series data during the peak growing season to develop an advanced crop yield algorithm (Lobell et al. 2015, Sibley et al. 2014). Thirdly, satellite data can only observe certain features that are correlated with crop yield but are unable to direct detect grain weight. To illustrate this point, we explain the growth cycle of paddy rice (Figure 1).

The International Rice Research Institute (IRRI) classifies the growth of paddy rice into two stages, the vegetative stage and the reproductive stage (IRRI 2013). The reproductive stage is subdivided into two periods-before and after the heading (i.e., anthesis or flowering); and the period after heading, also referred to as the ripening stage. During the vegetative stage, plants expand in height, increase in leaf number, size, and tillers, all of which leads to a gradual increase in total aboveground biomass ( $A G B$ ). Before the ripening stage, plants experience the fastest plant height increase; panicle initiation; booting (bulging of the leaf stem that conceals the developing panicle); heading (fully visibility of the panicle); and flowering (1 day after the completion of heading, lasting 7 days) (IRRI 2013). Since the flowering period determines the number of flowers, and each flower can only lead to one spikelet/one grain, the flowering period largely determines the potential grain yield (i.e., the number of grains).

When rice enters the ripening stage, the number of grains is fixed, and only the size of the grain increases (also known as "grain-filling"). The final grain yield is a product of the number of grains and the average size of all grains per unit area. Thus, both flowering and grain-filling periods are important 
in determining final rice yield. These two processes are sensitive to environmental conditions, especially during the flowering period (Fischer, Byerlee, and Edmeades 2014). Agronomically, the combined flowering and grain-filling process largely determine the harvest index, defined as the ratio of final crop yield divided by the total AGB (equation 1 ):

$$
\text { Crop yield }=\text { Aboveground biomass } \times \text { Harvest index }
$$

From a remote sensing perspective, crops experience the most dramatic changes in height and $A G B$ during the vegetative stage and early reproductive stage. The associated morphological and spectral changes are usually well captured using satellite data (both optical and microwave). For example, the Green Leaf Area Index reaches its peak value usually during the booting period (Chang, Shen, and Lo 2005). ${ }^{2}$ However, it is challenging to capture the flowering and grain filling processes using satellite data (Guan et al. 2015). This is either because these processes happen under the canopy or inside the hull of the final grain. Rice is different from corn and soybean in that corn and soybean both have their final grains below the canopy, while rice grains mostly locate at top of the canopy. This unique feature provides some possible foundation that $\mathrm{X}$-band radar backscatter may detect grain weight during the ripening stage (Inoue, Sakaiya, and Wang, 2014b; Inoue and Sakaiya 2013). However, this possibility is still inconclusive with many confounding factors, and is also hard to scale up due to the lack of X-band radar data. Meanwhile, optical sensor data are essentially unable to detect the harvest index process. Based on the above rationale, we argue that satellite data is most useful to capture AGB information but not harvest index information.

The above reasoning provides the foundation for using $A G B$ to approximate yield through three major sources: (i) an optical data derived vegetation index (e.g., normalized difference vegetation index [NDVI], enhanced vegetation index [EVI]) (Chang, Shen, and Lo 2005; Patel et al. 1991, Son et al. 2013); (ii) microwave-based backscatters (mostly C-band in previous studies) (Chen and Mcnairn 2006; Inoue, Sakaiya, and Wang 2014a; Kurosu and Chiba 1995); or (iii) calculations based on net primary production using light-use efficiency (Peng et al. 2014, Savin and Isaev 2011). Meanwhile, it is important to clarify that AGB does not explain all the variation in yield, and harvest index has to be separately modeled and incorporated in the yield modeling. The modeling of harvest index usually can be achieved by using process-based crop models (Lobell et al. 2015, Shen et al. 2009) or empiricalbased approach (Prasad et al. 2007, Xu and Guan 2017).

The objective of this paper is to build a prototype to map paddy rice fields and estimate crop yield in Thai Binh, using multiple satellite data sources: Landsat, MODIS, ALOS-2/PALSAR-2; and field data collected through crop cutting activities during the rainy season of 2015 . This study contributes to the growing literature on yield estimation using remote sensing techniques in several ways. Firstly, we are using the Landsat-MODIS fusion data for crop yield estimation. This fusion data provides a unique way to obtain high resolution data in both space and time, which is critical for estimating rice area and yields in settings where smallholder farms are prevalent. Secondly, we are also comparing the utility of L-band ALOS-2 radar data in mapping rice area and estimating crop yield, and comparing it with two alternatives, one using only optical data, and another combining both optical and radar data.

2 The Green Leaf Area Index is defined as the one-sided green leaf area per unit ground surface area. It is the area that is undergoing most activity during the photosynthesis process (Gitelson 2003). 
Figure 1: Growth Cycle of Paddy Rice: A Conceptual Framework to Model Crop Yield

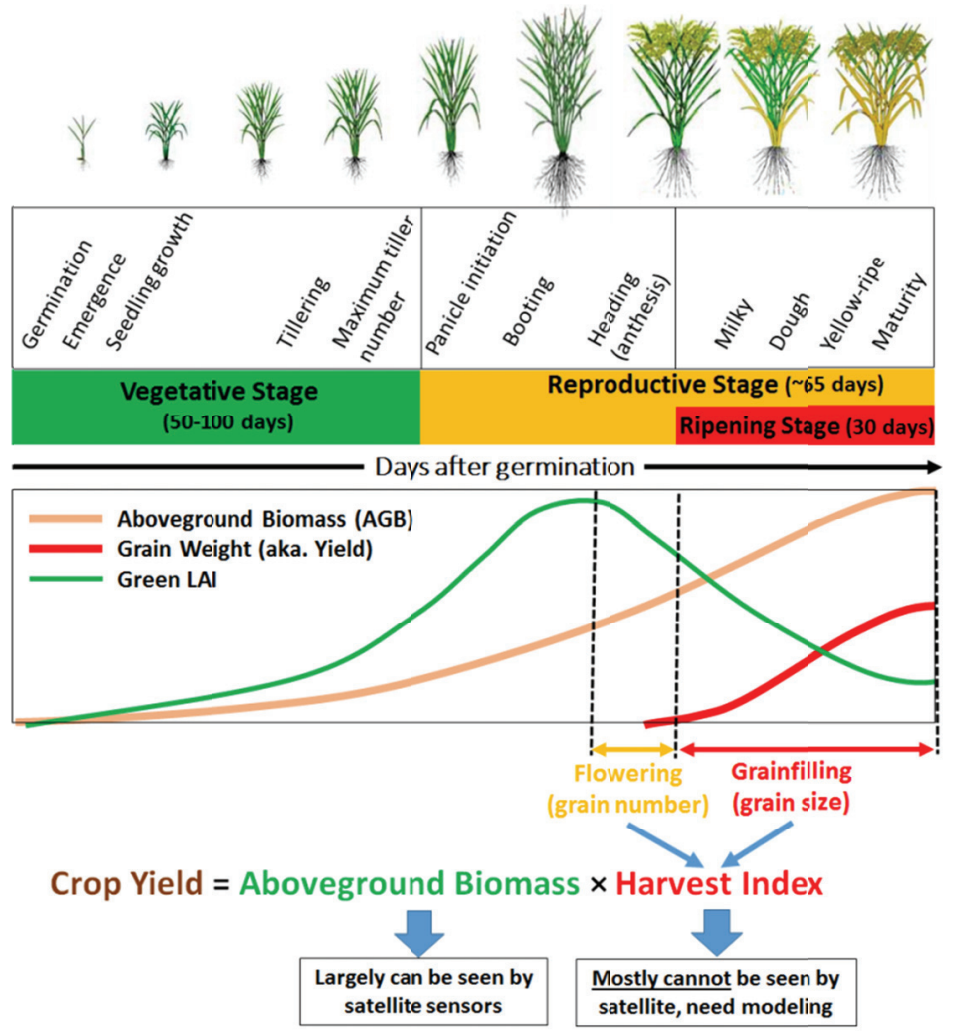

$\mathrm{LAI}=$ Leaf Area Index.

Source: Adapted from IRRI: http://www.knowledgebank.irri.org/images/stories/crop-calendar-growth-dsr.jpg.

\section{DATA AND METHODOLOGY}

\section{A. Study Area}

The study area includes the province of Thai Binh, located in northeastern coastal Viet Nam. Thai Binh is a key paddy rice production area in the Red River Delta region which is the second largest paddy rice-producing region in Viet Nam. Paddy rice is grown twice a year-during summer (mid-June to early October) and winter (mid-December to late May). With a total land area of 1,542 square kilometers, Thai Binh has one key rainy season which starts in May and ends in October. Total rainfall in Thai Binh during the rainy season is about 1,445 millimeters $(\mathrm{mm})$, accounting for approximately $85 \%$ of the total annual rainfall of $1,704 \mathrm{~mm} .{ }^{3}$ The average temperature across the year is from $19^{\circ} \mathrm{C}$ to $32^{\circ} \mathrm{C}$. Our study focuses on the summer growing season of 2015.

3 Rainfall data gathered from https://en.climate-data.org/location/4256/. 


\section{B. Landsat-MODIS Fusion}

One of the major hurdles to pursuing paddy rice area mapping and yield estimation using remote sensing techniques is the lack of available satellite data that have both high spatial and temporal resolutions. To overcome this challenge, we fuse the surface reflectance data from Landsat (16-day, $30 \mathrm{~m}$ ) and MODIS (daily, 250-500 m) to generate a fusion product that has both high spatial and high temporal resolution.

For Landsat data, we use surface reflectance data products from Landsat 7 and Landsat 8 , obtained from the United States Geological Survey (USGS) Earth Explorer. ${ }^{4}$ The entire study area can be covered by Worldwide Reference System (WRS)-2 path 126 and row 46. All Landsat surface reflectance data in the study area were screened and only scenes with more than $5 \%$ valid pixels ratio were downloaded and used. Table 1 lists all Landsat scenes used in the study. It is worth noting that the Scan Line Corrector (SLC) in Landsat 7, used for compensating for the forward motion of the onboard sensor, had failed in May 2003. This created data loss in the form of stripes (see examples of original Landsat for date of year (DOY) 231 and 295 in Figure 3). On average, about 22\% of pixels in Landsat 7 images were lost because of the SLC failure.

Table 1: Landsat Scenes Used in the Landsat-MODIS Fusion

\begin{tabular}{llc}
\hline Satellite & \multicolumn{1}{c}{$\begin{array}{c}\text { Date } \\
\text { (Julian day) }\end{array}$} & $\begin{array}{c}\text { Valid Pixel Ratio } \\
(\%)\end{array}$ \\
\hline Landsat 7 & April 2013 (103) & 78.63 \\
& May 2015 (135) & 43.34 \\
& July 2002 (183) & 77.88 \\
& August 2019 (231) & 79.63 \\
Landsat 8 & October 2022(295) & 76.32 \\
& January 2015(15) & 60.52 \\
& June 2008 (159) & 10.41 \\
& July 2010 (191) & 90.96 \\
& August 2011 (223) & 5.03 \\
& August 2027 (239) & 62.35 \\
& September 2028(271) & 44.07 \\
& October 2030 (303) & 38.98 \\
& November 2015(319) & 15.82 \\
& December 2001(335) & 48.70 \\
\hline
\end{tabular}

MODIS = Moderate Resolution Imaging Spectroradiometer.

Source: NASA Landsat Science. 2017. Data: The Numbers Behind Landsat. https://landsat.gsfc.nasa.gov/data/.

For MODIS data, both Terra and Aqua data were used and acquired from the National Aerospace Space Agency (NASA). ${ }^{5}$ Specifically, daily MODIS surface reflectance data at $250 \mathrm{~m}$ (red and near-infrared band) and $500 \mathrm{~m}$ (other spectral bands) resolution from Terra (MOD09GQ/MYD09GA) and Aqua (MYD09GQ/MYD09GA) bands are normalized to the Nadir BRDF-Adjusted Reflectance data using the 8-day overlapping MODIS BRDF/Albedo product (MCD43A1, $500 \mathrm{~m}$ ). Two MODIS tiles, h28v06 and h27v06, are required to cover the whole study area (Table 2).

This study employs a mature Landsat-MODIS fusion algorithm, the Spatial and Temporal Adaptive Reflectance Fusion Model (STARFM) (Gao et al. 2006). STARFM model blends Landsat and MODIS data to generate synthetic daily surface reflectance products at Landsat spatial resolution

4 Data sourced from http://earthexplorer.usgs.gov/.

5 Data sourced from http://reverb.echo.nasa.gov/. 
based on a deterministic weighting function computed by spectral similarity, temporal difference, and spatial distance. The algorithm requires Landsat and MODIS pair images for the same date with clearday quality. This posed several challenges for our study (Chen et al. 2011). First, no single completely clear Landsat scene was available in the study area due to cloud contamination and the SLC-off problem, which limited the selection of Landsat-MODIS pair images. To address this issue, we used a gap-filling algorithm called Geostatistical Neighborhood Similar Pixel Interpolator (Zhu, Liu, and Chen 2012). Second, the ratio of valid pixels of MODIS images from both Terra and Aqua were also limited due to clouds. For example, there were more than 76\% MODIS images from Aqua, and 80\% MODIS images from Terra with a low valid pixels ratio ( $<10 \%)$. No more than $6.0 \%$ and $4.2 \%$ of images from Aqua and Terra showed a relatively high valid pixels ratio (>80\%). After checking all the pair images, we found that the Landsat 7 (after gap filling) and MODIS images on DOY 103 both have valid pixels of more than 95\%. Thus, we use this pair of MODIS and Landsat images to train the STARFM algorithm and apply it to the rest of the MODIS images when MODIS surface reflectance data is available. Due to the setup of the STARFM algorithm, only limited Landsat data are used in the fusion process, even when there are several other Landsat data available at other dates with some clear-sky pixels. To fully leverage these Landsat data, we combine the MODIS-Landsat fused data and the raw Landsat data when we study the time series of the target pixels

\section{ALOS-2/PALSAR-2 Data}

Launched on 24 May 2014, ALOS-2 is equipped with an enhanced Phased Array L-band SAR sensor (PALSAR-2) (Rosenqvist et al. 2014). As a successor to a previous ALOS mission from January 2006 to May 2011, the satellite acquires global L-band data, thereby assuring continuity in availability of data and consistency with the overall objectives of Japan Aerospace Exploration Agency. ALOS-2 is in a 628kilometer sun-synchronous orbit, with a local equator passing time of 12:00 p.m. (descending passes) and 12:00 a.m. (ascending passes), and a 14-day repeat cycle. PALSAR-2 operates in the 1215-1300 megahertz $(\mathrm{MHz})$ frequency range with four different bandwidths $(14,28,42$, and $84 \mathrm{MHz})$. Four images of Level-2.1 PALSAR-2 product were acquired for this study at 25-meter resolution, covering the following dates: 24 June, 22 July, 16 September, and 14 October in 2015. These images were resampled using PALSAR-2's Stripmap observation mode to convert data into 10-meter resolution within the 28 $\mathrm{MHz}$ band. Table 2 shows the satellite data information for Landsat, MODIS, and ALOS-2 sensors.

Table 2: Satellite Data Information in the Study Area

\begin{tabular}{llll}
\hline Sensors & Data & Properties & Tiles \\
\hline Landsat & Landsat 7 and 8 & Land surface reflectance and cloud mask & Path126/Row046 \\
MODIS & MOD09GQ & Daily surface reflectance data (250 m) & H27V06 and \\
& MYD09GQ & & H28v06 \\
& MOD09GA & Daily surface reflectance (500 m), angle information (1 & \\
& MYD09GA & km), QA (1 km) & \\
& MCD43A1 & $\begin{array}{l}\text { Terra and Aqua combined MODIS BRDF/Albedo model } \\
\text { parameters (500 m, 8-day overlapping) }\end{array}$ & \\
& MCD12Q1 & MODIS land cover (500 m) \\
ALOS-2 & PALSAR-2 & L-band radar backscatter (HV, HH) for four dates (DOY & \\
& & 175, 203, 259, 287) & \\
\hline
\end{tabular}

ALOS = Advanced Land Observing Satellite, $B R D F=$ bidirectional reflectance distribution function, $\mathrm{DOY}=$ date of year, $\mathrm{HH}=$ horizontal transmit and horizontal receive, $\mathrm{HV}=$ horizontal transmit and vertical receive, $\mathrm{km}=$ kilometer, $\mathrm{m}=$ meter, $\mathrm{MODIS}=$ Moderate Resolution Imaging Spectroradiometer, QA = quality assurance.

Source: U.S. Geological Survey 2014, 2016, 2017a, and 2017b. 


\section{Paddy Rice Mapping and Land Cover Classification}

To identify paddy rice area from satellite images, we classify the land cover of Thai Binh into six categories, based on the International Geosphere-Biosphere Programme classification scheme used by MODIS global land cover product (Friedl et al. 2002). The six classes were selected based on our visual interpretation of high-resolution images on Google Earth and the knowledge from local field crew (Table 3). Since paddy rice is the predominant crop grown in Thai Binh during the rainy season, the category "Croplands" refers to paddy rice in our study.

Our land cover classification uses a random forest classifier algorithm (Breiman 2001), which has been widely tested and proved robust and efficient in the classification of remote sensing images (Hansen et al. 2000; Pal 2005; Zhu, Fu, Woodcock, Olofsson, Vogelmann, Holden, and Yu 2016; Zhu et al. 2012). We test four types of input datasets for the classification (Table 4). The training pixels were selected as evenly as possible across the spatial extent of the images and excluded from pixel sampling during the assessment of classification accuracy.

For the classification accuracy assessment, we follow the protocol set up by Olofsson et al. (2014). We obtain the conjectured overall accuracy and user's accuracy from the cross validation of random forest classifier and prescribe the expected standard errors of user's accuracy for the six classes as 0.01 for croplands, 0.05 for barren, 0.05 for built-ups, 0.02 for water, 0.05 for wetlands, and 0.10 for other vegetation. From the initial assessment of the classification accuracies and expected standard errors, we determine the total number of pixel samples needed for the assessment of each classification map and allocate these samples to each class using the approach by Olofsson et al. (2014). All the pixel samples are interpreted visually over the Landsat images and high-spatialresolution images on Google Earth from the similar period. We also consulted local field crew for the interpretation of a few uncertain pixel samples.

Table 3: Classification Scheme

\begin{tabular}{l|l}
\hline Class (code) & Definition \\
\hline Croplands (1) & $\begin{array}{l}\text { Lands covered with temporary crops followed by harvest and a bare soil period (e.g., single and multiple } \\
\text { cropping systems), excluding perennial woody crops, which are classified as natural vegetation. }\end{array}$ \\
\hline Barren (2) & $\begin{array}{l}\text { Lands with exposed soil, sand, rocks, or snow and never have more than 10\% vegetated cover during any } \\
\text { time of the year. Includes dry salt fields. }\end{array}$ \\
\hline Built-ups (3) & Land covered by buildings and other man-made structures. \\
\hline Water (4) & Fresh or saltwater bodies including oceans, seas, lakes, reservoirs, rivers, as well as wet salt fields. \\
\hline $\begin{array}{l}\text { Wetlands (5) } \\
\text { Other } \\
\text { vegetation (6) }\end{array}$ & $\begin{array}{l}\text { Lands with a permanent mixture of water and herbaceous or woody vegetation. The vegetation can be } \\
\text { present either in salt, brackish, or fresh water. }\end{array}$ \\
\hline
\end{tabular}

Source: Friedl, Mark A., Douglas K. Mciver, John C. F. Hodges, Xiaoyang Y. Zhang, Douglas M. Muchoney, and Alan H. Strahler. 2002. "Global Land Cover Mapping from MODIS: Algorithms and Early Results." Remote Sensing of Environment 83 (1-2): 287-302. 
Table 4: List of Input Datasets for Land Cover Classification

\begin{tabular}{l|lc}
\hline Short Name & Description of Input Datasets for Classification & $\begin{array}{c}\text { Number of } \\
\text { Features }\end{array}$ \\
\hline Landsat only & $\begin{array}{l}\text { Six bands a of three, mostly cloud-free Landsat images: ETM+ }{ }^{\text {b }} \text { on 13 April and } 8 \\
\text { July; OLI on 10 July in 2015 }\end{array}$ & 18 \\
\hline ALOS-2 only & $\begin{array}{l}\text { HH and HV bands of four ALOS-2 images on 24 June, 22 July, 16 September, } \\
\text { and 14 October in 2015 }\end{array}$ & 8 \\
\hline Landsat + ALOS-2 & Combination of the above Landsat and ALOS-2 imagery datasets & 365 \\
\hline Fusion NDVI SG fit & $\begin{array}{l}\text { Interpolated NDVI time series from the SG fit to the fusion images of Landsat } \\
\text { and MODIS data in 2015 }\end{array}$ & 365 \\
\hline
\end{tabular}

ALOS $=$ Advanced Land Observing Satellite, ETM+ = Enhanced Thematic Mapper Plus, GNSPI = Geostatistical Neighborhood Similar Pixel Interpolator, $\mathrm{HH}=$ horizontal transmit and horizontal receive, $\mathrm{HV}=$ horizontal transmit and vertical receive, MODIS = Moderate Resolution Imaging Spectroradiometer, NDVI = normalized difference vegetation index, OLI = Operational Land Imager, SLC = Scan Line Corrector, SG = Savitzky-Golay.

Notes:

${ }^{a}$ List of six bands: blue, green, red, near infrared, and two shortwave infrared.

${ }^{b}$ ETM+ SLC-off gaps have been filled using GNSPI algorithm.

Source: Zhu, Zhe, Curtis E. Woodcock, John Rogan, and Josef Kellndorfer. 2012. "Assessment of Spectral, Polarimetric, Temporal, and Spatial

Dimensions for Urban and Peri-Urban Land Cover Classification using Landsat and SAR Data." Remote Sensing of Environment 117: $72-82$.

\section{E. Crop Yield Estimation}

\section{Crop Cutting Data}

A three-stage stratified sampling methodology was employed for the crop cutting survey, using an area frame that was constructed based on the expected likelihood of finding paddy rice area. Two sources of rice maps were utilized to implement the stratification process: rice extent maps produced by IRRI using 2015 MODIS data; ${ }^{6}$ and (ii) land use maps produced by the European Space Agency (ESA) under its GLOBCOVER initiative. 7 The stratification was conducted prior to the selection of meshes to improve statistical efficiency and lower fieldwork costs. The primary sampling unit in this study is a 200 $\mathrm{m}$ by $200 \mathrm{~m}$ square "mesh" that is spatially defined on a digitized satellite image map.

The first stratum, or the IRRI+ESA stratum, consists of meshes that both IRRI and ESA maps have identified as paddy rice area, therefore considered to be the most likely to contain paddy rice. The second stratum, also known as the IRRI stratum, consists of meshes that were only identified as rice by the IRRI map but not by the ESA map. This is considered a medium-probability stratum for two reasons-(i) the spatial resolution of the IRRI map is better than that of the ESA map, and (ii) IRRI's classification is more recent than ESA's. ${ }^{8}$ The third stratum is the low-probability ESA stratum, which consists of areas identified as rice by ESA's map but not by IRRI's map. The final stratum consists of all

6 IRRI has been developing remote sensing-based maps of rice systems in Asia as part of its contribution to various projects that need good baseline data on rice (http://irri.org/our-work/research/policy-and-markets/mapping/remote-sensingderived-rice-maps-and-related-publications).

7 GlobCover began in 2005 as a European Space Agency initiative in partnership with the Joint Research Center, United Nations Environment Programme, Food and Agriculture Organization, and other institutions. The aim of the project was to develop a service capable of delivering global composites and land cover maps using input observations from a sensor on board the ENVISAT mission (http://due.esrin.esa.int/page_globcover.php).

8 IRRI's map was created using MODIS data, which has a spatial resolution of $250 \mathrm{~m}$, while ESA's map was created using Environmental Satellite (ENVISAT) data, which has a spatial resolution of 300 m. IRRI's map uses satellite data from 2015 while ESA's map is constructed using data from 2009. 
remaining areas where presumably no rice is grown, as indicated by both IRRI's and ESA's maps. This stratum is henceforth referred to as the Other stratum. Therefore, within each stratum, the entire area was conceptually divided systematically into 200 m by 200 m meshes using geographic information system techniques.

In the first sampling stage, a stratified sample of 120 meshes was selected. The number of selected meshes was higher in the stratum where the expectation of finding rice growing plots is highest (IRRI+ESA), and lower in areas with low or no likelihood of finding rice growing plots (ESA and Other, respectively). All the sample meshes were checked in the field to determine whether rice was planted in any plots within the mesh boundaries. Only sample meshes with rice were enumerated for the Rice Crop Cutting Survey. The final distribution of the sample meshes with rice planted in Thai Binh is shown in Table 5.

\section{Table 5: Distribution of Sample Meshes by Stratum for the Crop Cutting Survey in Thai Binh, Viet Nam}

\begin{tabular}{lccc}
\hline Stratum & $\begin{array}{c}\text { Sample Meshes } \\
\text { Selected }\end{array}$ & $\begin{array}{c}\text { Sample Meshes } \\
\text { Surveyed }\end{array}$ & $\begin{array}{c}\text { Sample Meshes } \\
\text { with Rice }\end{array}$ \\
\hline IRRI+ESA & 80 & 79 & 63 \\
IRRI & 20 & 20 & 2 \\
ESA & 15 & 15 & 7 \\
Others & 5 & 5 & 0 \\
Total & 120 & 119 & 72 \\
\hline
\end{tabular}

ESA = European Space Agency, IRRI = International Rice Research Institute.

Note:

${ }^{a}$ One sample mesh under the IRRI+GlobCover stratum was not visited due to inaccessibility during fieldwork.

Source: Authors' estimates.

For the second sampling stage, a field-based listing of all rice plots identified with at least part of their area within the boundaries of each sample mesh was conducted. All plots where rice would be harvested during the rainy season of 2015 were eligible to be selected in the second sampling stage. Plot boundaries were defined based on the definition adopted by the Living Standards Measurement Study Group of the World Bank (Carletto et al. 2016): a "plot" is a continuous piece of land on which a unique crop or a mixture of crops is grown under a uniform, consistent crop management system, which is continuous and not split by an obstruction (e.g., river or path, etc.) of more than $1 \mathrm{~m}$ in width; and whose plot boundaries are defined according to the crops grown, and the operator.

A printed map of each of the $200 \mathrm{~m} \times 200 \mathrm{~m}$ sample meshes was used to identify the number of plots that fall within each mesh. Landmarks on the printed map were matched with what is observed on the field. Boundaries of the mesh were verified using a Global Positioning System (GPS) application installed on the handheld device used for fieldwork, which showed the field staff's current position in relation to the mesh. The plot boundaries and the respective owners were identified with the help of the village heads.

After the boundaries of all the plots were identified and delineated on the printed map, each plot was numbered in a geographically serial and serpentine manner. A listing form was used to transfer information of all plots within a sample mesh from the printed map, which helped identify the total number of plots covering the extent of the sample mesh. Only plots that were either completely or partially inside the sample mesh were included in the listing process. 
A sample of four plots per mesh was randomly selected for crop cutting from the list of plots that met the selection criterion. The selection of four plots was driven by the need to ensure sufficient sample size within a mesh to capture variability in rice yields across plots, and budgetary constraints. For those sample meshes with four or less plots that were eligible for selection, crop cutting was done in all plots. If there were more than four plots within the mesh, crop cutting was implemented only on four randomly selected plots. A simple systematic random sampling approach was used for the plots.

At the third sampling stage, a random point was selected within each sample plot to identify a $2.5 \mathrm{~m}$ by $2.5 \mathrm{~m}$ crop cutting subplot. A total of 256 plots underwent the crop cutting activities, which includes harvesting, drying, threshing, cleaning, and moisture reading. Data from these 256 randomly selected subplots were ultimately used for filtering crop cutting data as described in the next section.

Training of field staff on crop cutting activities was conducted in September 2015. The actual fieldwork took place between late September 2015 and early November 2015, covering the period associated with rice harvesting in Thai Binh. The questionnaires were administered on paper in Vietnamese language. In addition to implementing crop cutting procedure on selected plots, ancillary information on household members, plot characteristics, and crop variety was also collected. Questionnaires were verified by supervisors on the field and subsequently returned to the headquarters of the Center for Informatics and Statistics in Hanoi where double data entry and data cleaning activities were undertaken to produce a clean dataset used for analysis.

\section{Crop Yield Estimation Algorithm}

Based on the proposed methodology in Figure 1, ideally, we need to know both the AGB and harvest index. AGB usually can be approximated by the peak vegetation index, which can be derived from the Landsat-MODIS fusion data through a curve fitting from the fused data points. Harvest index requires spatially variable weather data and/or multiple-season data to capture the impact of climatic conditions. In this study, we only have crop cutting data for one growing season. Also, given the relatively small area of Thai Binh, there may not be significant variation in climatic variables across the province. Thus, we primarily focus on approximating AGB for yield estimation, under the assumption that all rice fields in the province share the same harvest index for the current growing season. We test multiple widely used vegetation indexes to approximate AGB, including NDVI (Sellers et al. 1992, Tucker 1979); EVI (Huete et al. 2002); and green chlorophyll vegetation index (GCVI) (Gitelson 2003, Lobell et al. 2015).

There are some challenges to conducting a curve fitting exercise to the 1-year time series of vegetation indexes from the Landsat-MODIS fusion data at $30 \mathrm{~m}$ resolution. First, the cloud cover still causes large gaps after the data fusion (Figure 2), leading to insufficient data points in the 1-year time series to properly constrain the fitting of commonly used phenological curves of different complexities, such as double logistic, asymmetric Gaussian, and Savitzky-Golay filter (Chen, Deng, and Chen 2006; Guan et al. 2014; Jönsson and Eklundh 2002; Zhang et al. 2003). The gaps in our time series data span from around DOY 200 to 220, the greenup phase of the second season (Figure 2) for almost all the pixels of field subplots, and from around DOY 250 to 280, the senescence phase for many pixels (Figure 2, top panel). Neither the double logistic or Savitzky-Golay filter correctly captured the peak vegetation index of the second crop growing season due to large temporal gaps. Furthermore, most curve fitting algorithms for time series of vegetation indexes assume that noises in the data are mostly caused by residual cloud contamination that underestimate vegetation index, and thus try to find the upper envelope of a time series (Chen, Deng, and Chen 2006; Chen et al. 2004; Jönsson and Eklundh 2002). However, our time series data from the Landsat-MODIS fusion includes both positive and negative noises that could come from the fusion algorithm STARFM itself due to the shortage of clear- 
sky image pairs between Landsat and MODIS and/or from the uncertainty of the SLC-off gap filling by Geostatistical Neighborhood Similar Pixel Interpolator. The two time series examples in Figure 2 show some clear positive noise points around DOY 220 and after DOY 300.

To overcome the large gaps and the noises of both positives and negatives in our time series data, we use a simple quadratic curve fitting method to derive peak vegetation indexes of the second growing season. The quadratic curve is centered at DOY 250, which was determined by visually inspecting many time series of crop pixels distributed over the study area. To reduce the impact of noises in the time series to our peak estimation, we calculate the standard deviation of the fitted curve and remove vegetation index values beyond three standard deviations from the mean. Then a new curve is fitted to the remaining vegetation index values. This procedure is repeated iteratively until all the vegetation index values for the curve fitting are within the confidence interval of the curve fitting.

The derived peak vegetation index values of the pixels of all the representative field subplots are then regressed against the yield data from crop cutting. We use NDVI, EVI, and GCVI peak values, respectively to derive univariate linear regression models. We also tried multivariate linear regression by combining each of these optical-based vegetation indexes with ALOS-2 backscatter from $\mathrm{HH}$ or HV or both on the 2 available days (16 September and 14 October) in the second growing season. However, these multivariate regression models do not improve the univariate model estimates, based on the Akaike information criterion scores. Thus, we focus on the univariate regression models using the three optical-based vegetation indexes in our crop yield estimation.

Figure 2: Examples of How Peak Values of Normalized Difference Vegetation Index were Derived from the Landsat-MODIS Fusion Data

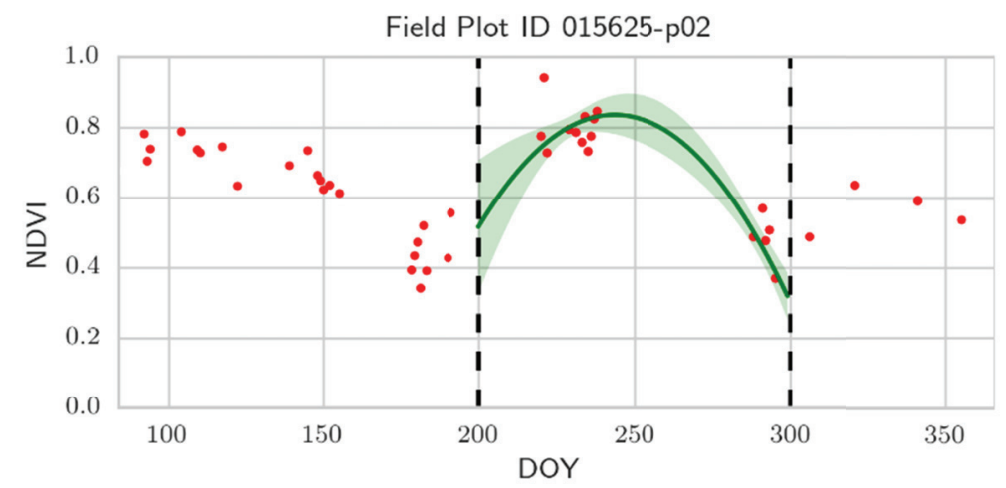

Field Plot ID 043402-p09

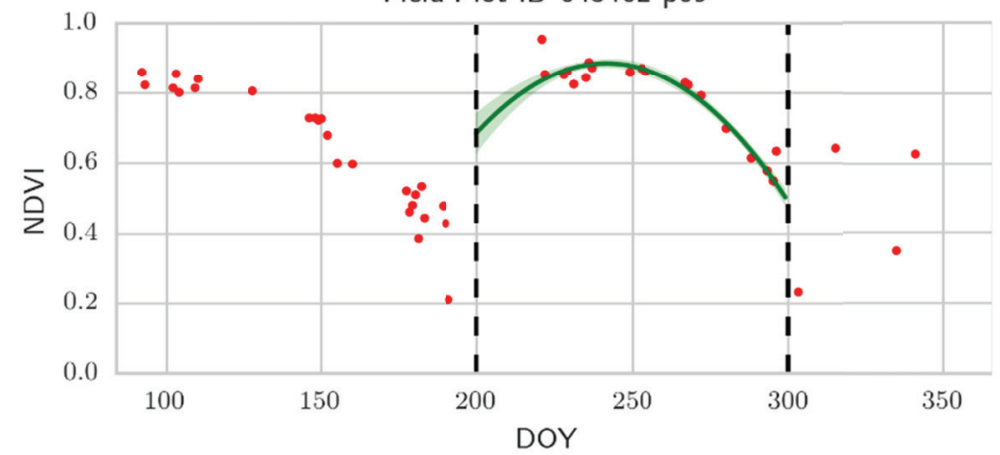

DOY = date of year, MODIS = Moderate Resolution Imaging Spectroradiometer, NDVI = normalized difference vegetation index. Source: Authors' estimates. 


\section{RESULTS}

\section{A. Landsat-MODIS Fusion}

Figure 3 shows a typical example of a $30 \mathrm{~m}$ by $30 \mathrm{~m}$ pixel time series from both the Landsat-MODIS fusion data (Figure 3 top panel) and original Landsat data (Figure 3 bottom panel). We can see clearly two growing cycles from the NDVI data from the two sources of this example pixel, with the first growing season ending around DOY 190, and the second growing season peaking around DOY 250. For our study region, it is a common situation that there is a gap in data from DOY 195 to 220, which is a period characterized by continuous rainy events and cloudy conditions. It is worth noting that if we only rely on Landsat data, we will not have a clear-day scene during the peak growing season around DOY 250 as shown in Figure 3. Only through the fusion approach can we recover the information during the peak value of NDVI for the second growing season.

Figure 3: Normalized Difference Vegetation Index Time Series

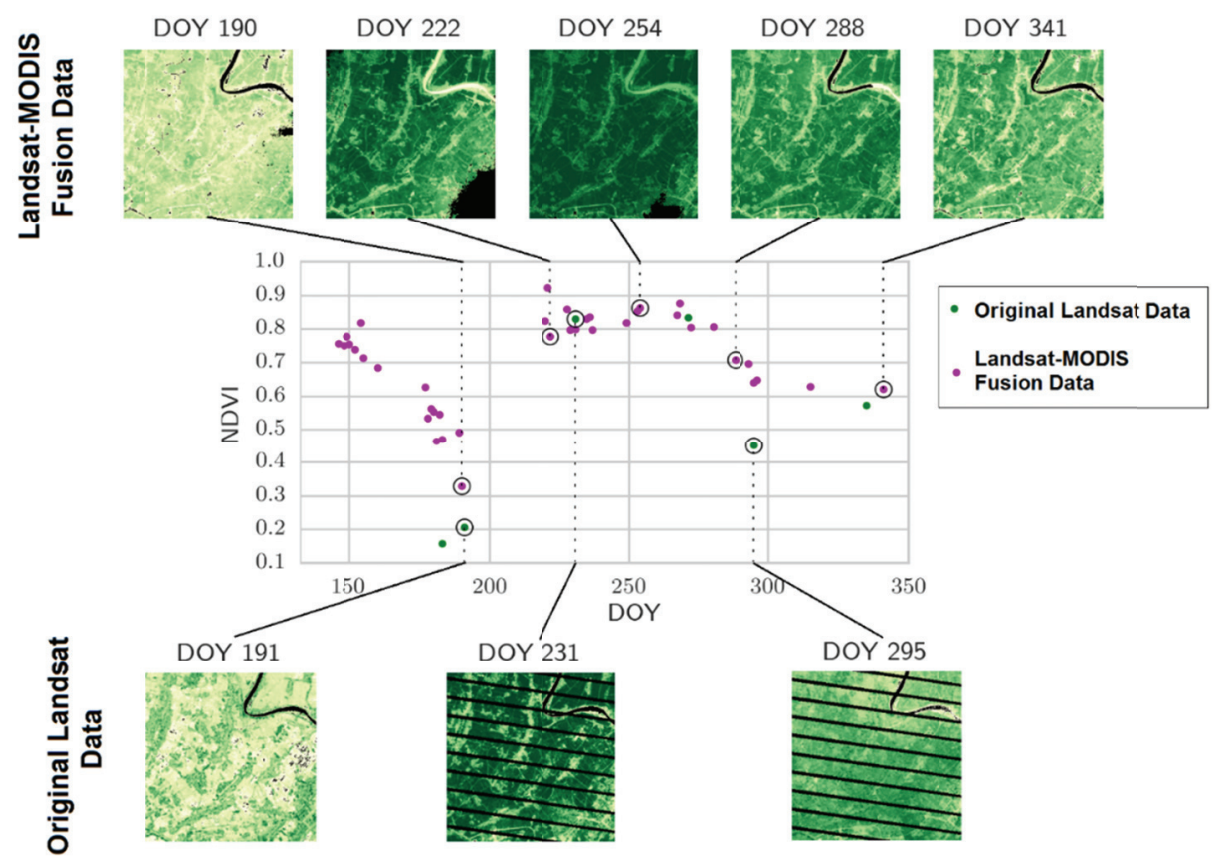

DOY = date of year, $\mathrm{m}=$ meter, $\mathrm{MODIS}=$ Moderate Resolution Imaging Spectroradiometer, NDVI = normalized difference vegetation index.

Notes: The series shows a $30 \mathrm{~m}$ by $30 \mathrm{~m}$ pixel that combines the original Landsat data (in green points) and the Landsat-MODIS fused data (in purple points). The top and bottom rows show the image data $(3,000 \mathrm{~m}$ by $3,000 \mathrm{~m})$ that correspond to different time stamps, and the corresponding DOY and NDVI values at the central of the image. The second rice growing cycle starts around DOY 200.

Source: Authors' estimates. 


\section{B. Paddy Rice Mapping}

The overall accuracy associated with classifying landcover of Thai Binh using four different inputs are ranked from high to low as: (i) "Landsat + ALOS-2," (ii) "Landsat only," (iii) "Fusion NDVI SG Fit," and (iv) "ALOS-2 only" (Figure 4). The difference between the first two inputs, "Landsat + ALOS-2" and "Landsat Only" is small, $0.77 \pm 0.02$ versus $0.76 \pm 0.02$. (see Table A.1 and A.2 in the appendix). For the class of our main interest here, paddy rice, user's accuracy follows the same ranking order across the four inputs. The producer's accuracy of paddy rice is the highest for the input "Fusion NDVI SG Fit" despite the lower user's accuracy and the relatively low overall accuracy. This high producer's accuracy and low omission error comes from the sacrifice of the other classes (see Table A.3 in the appendix), which suggests that temporal information from NDVI alone is not sufficient to clearly separate the land cover types over this region. Approaches that include the six bands from three Landsat images in the classification rank first and second place in the overall accuracies, which demonstrates the importance of the spectral information from the Landsat sensors (see Table A.4 and A.5 in the appendix). Future experiments to use time series of all the six bands from the Landsat sensors may further improve the classification, particularly the producer's accuracy of paddy rice.

By merging all the maps from the four inputs, the derived final land cover map shows accuracy levels similar to the "Landsat + ALOS-2" input (Figure 4). The overall accuracy is $0.77 \pm 0.02$ for landcover types, user's accuracy is $0.91 \pm 0.01$, and producer's accuracy is $0.88 \pm 0.02$ for paddy rice. Figure 5 shows the final land cover classification map produced by merging the four inputs.

Figure 4: Results from Using Four Different Inputs

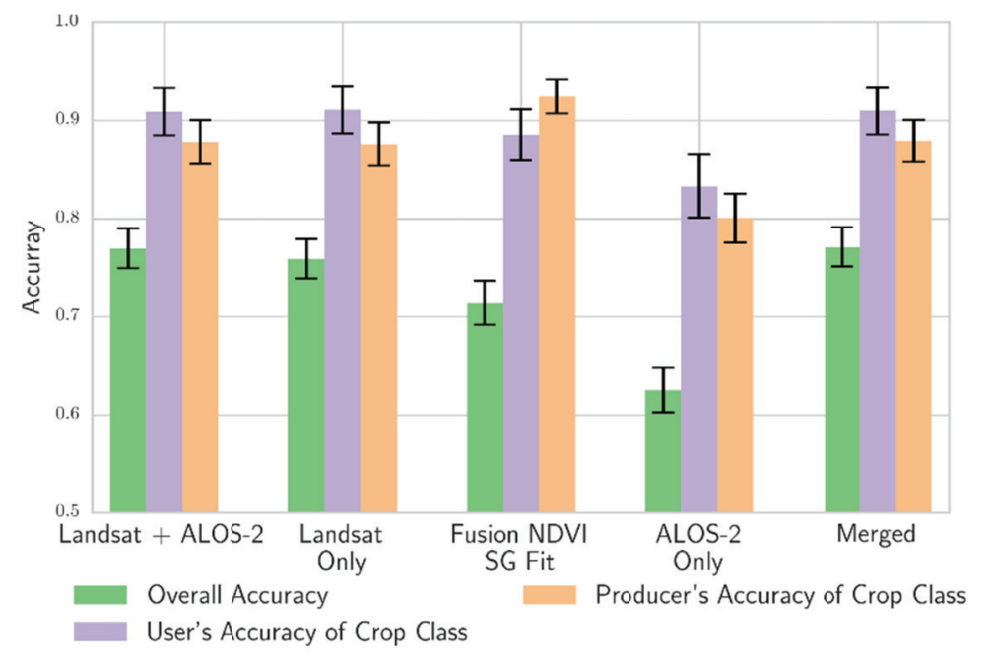

ALOS = Advanced Land Observing Satellite, NDVI = normalized difference vegetation index, SG = SavitzkyGolay.

Source: Authors' estimates. 


\section{Figure 5: Classified Land Cover Map Resulting from Merging Four Inputs}

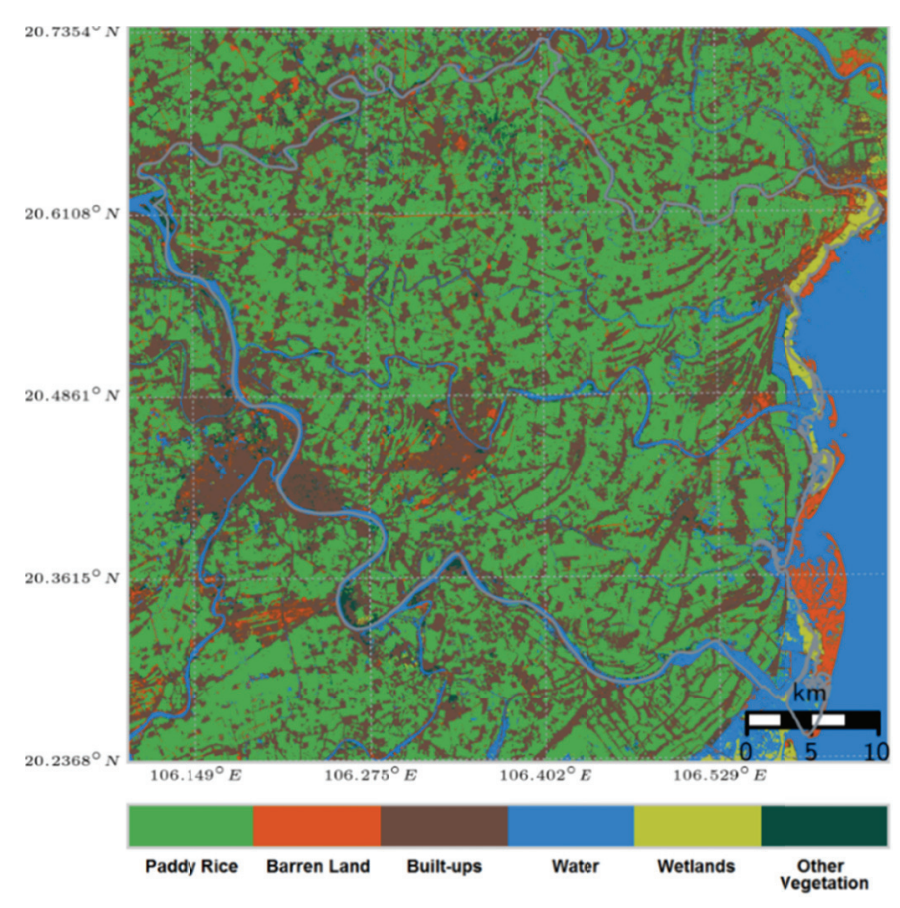

Source: Authors' estimates.

\section{Crop Yield Estimation}

\section{Field-Level Model Performance}

All the three vegetation indexes (NDVI, EVI, and GCVI) show some contribution to estimating crop yield at field or pixel level, as suggested by the low $p$ values of F-test against the null hypothesis of an intercept-only model (Figure 6). The NDVI-based model gives the best performance, as indicated by the $\mathrm{R}^{2}$ of 0.40 for all the representative field subplots (Figure 6, black solid line), the highest among the three vegetation indexes. As discussed in the introduction and methodology, vegetation index here can greatly explain AGB variability. The performance that we achieved ( $R^{2}$ of 0.40 at the field level) is among the highest performance achieved in previous studies that can provide reproducibility (Burke and Lobell 2017).

If we only include the dominant rice variety, $\mathrm{BC} 15$, in the regression, accounting for $58 \%$ of the representative subplots, the $\mathrm{R}^{2}$ increases significantly for all the three vegetation indexes (Figure 6 , purple solid line). This increase in the $\mathrm{R}^{2}$ value suggests that different crop varieties may lead to different relationships between vegetation indexes and crop yield, making the collection of crop variety information a crucial input. However, it is quite challenging to map the rice variety given the spatial resolution of the satellite data used in this study. In addition, the sample size of our current crop cutting data is not enough to provide robust yield models at the crop variety level. We therefore rely on a general model without differentiating rice varieties. 
We also find that the ALOS-2 backscatter bears little information for paddy rice yield prediction over this study region (Figure 7). The rank-based correlation coefficient, Spearman's $\rho$ is close to zero and the correlation is insignificant (high $p$ values) for both $\mathrm{HH}$ and $\mathrm{HV}$ bands of the two available images in the second growing season, one of which is from DOY 259 that is close to the peak vegetation index time around DOY 250.

\section{Scaling Up to the Whole Province and Regional Validation}

We apply the best yield estimation model, i.e., using peak NDVI for all the crop varieties, to the whole province of Thai Binh, shown in Figure 8 . The figure clearly shows a large spatial heterogeneity in crop yield from 3 tons per hectare ( $\mathrm{t} / \mathrm{ha}$ ) to $6.5 \mathrm{t} / \mathrm{ha}$, with the northern part of the province having the lowest crop yield, which is consistent with the local survey data.

Figure 6: Linear Regression Model between the Peak of Vegetation Indexes and Crop Yield

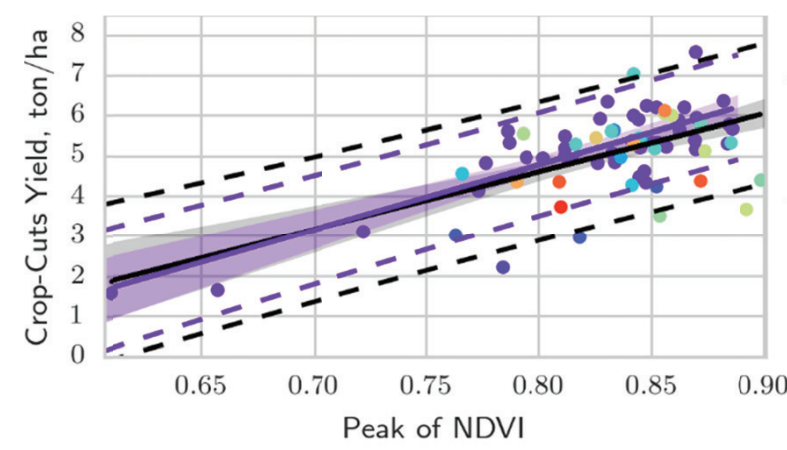

$$
\begin{aligned}
& y=14.40 \times x-6.91 \\
& R^{2}=0.40 \\
& p=2.88 e-09 \\
& \\
& y=16.23 \times x-8.20 \\
& R^{2}=0.69 \\
& p=2.18 e-11
\end{aligned}
$$

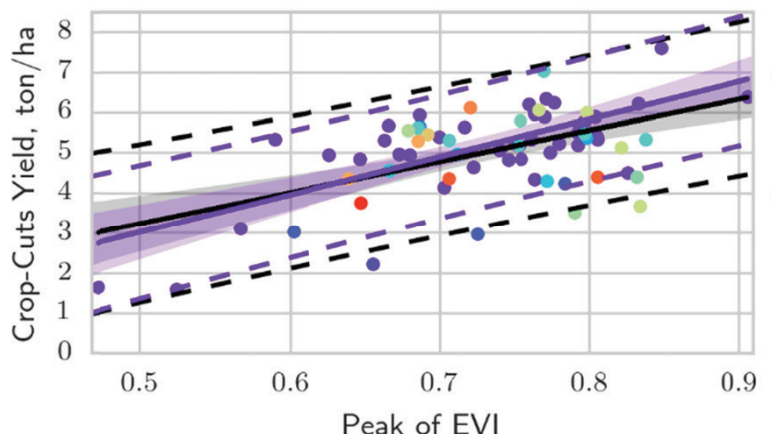

$$
\begin{aligned}
& \begin{array}{l}
y=7.76 \times x-0.66 \\
R^{2}=0.30
\end{array} \\
& p=6.02 e-07 \\
& y=9.40 \times x-1.69 \\
& \begin{array}{l}
y=9.40 \times \\
R^{2}=0.55
\end{array} \\
& p=2.79 e-08
\end{aligned}
$$

- $\mathrm{BC} 15$

- Thien Uu

- Bac Thom

- Khang Dan

- Thien Uu 8

- Nep97

- Q5

- Huong Thom 1

- Nep

- Nep Cai Hoa Vang

- Hoa Khoi

- 99

- TBR1

- M1

- DT68

- Bac Thom 7

- Lua Nep

_ prediction interval

- - for all crop varieties

_ _ prediction interval for $\mathrm{BC} 15$

confidence interval for all crop varieties confidence interval for $\mathrm{BC} 15$

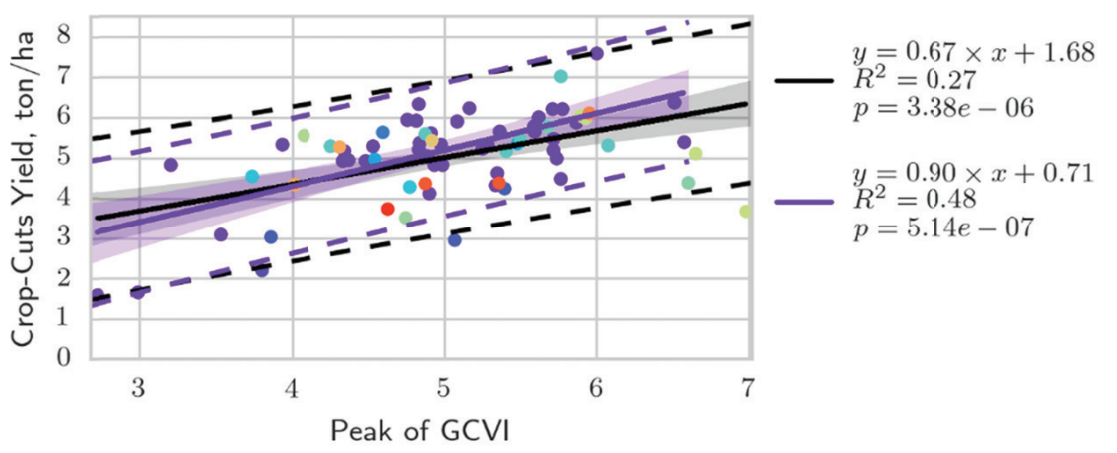

$\mathrm{EVI}=$ enhanced vegetation index, GCVI = green chlorophyll vegetation index, NDVI = normalized difference vegetation index. Notes: The vegetation indexes are NDVI, EVI, and GCVI. Crop yield for all the crop varieties are represented by the black line and BC15 by the purple line. Colors of the dots refer to different crop varieties.

Source: Authors' estimates. 
The probability density distribution of crop yield from the NDVI-based regression model within Thai Binh (not the whole image extent) is a near-normal distribution with a slight skew toward the low tail (Figure 9, blue bars). We derive the probability density distribution of crop yield (Figure 9, purple bars) from those field subplots that are not used in our regression and their area weights within the province given by the statistical extrapolation of field samples. The field-sampling-based distribution is bimodal at approximately from $5.0 \mathrm{t} /$ ha to $5.7 \mathrm{t} / \mathrm{ha}$, if we assume a normal distribution of crop yield.

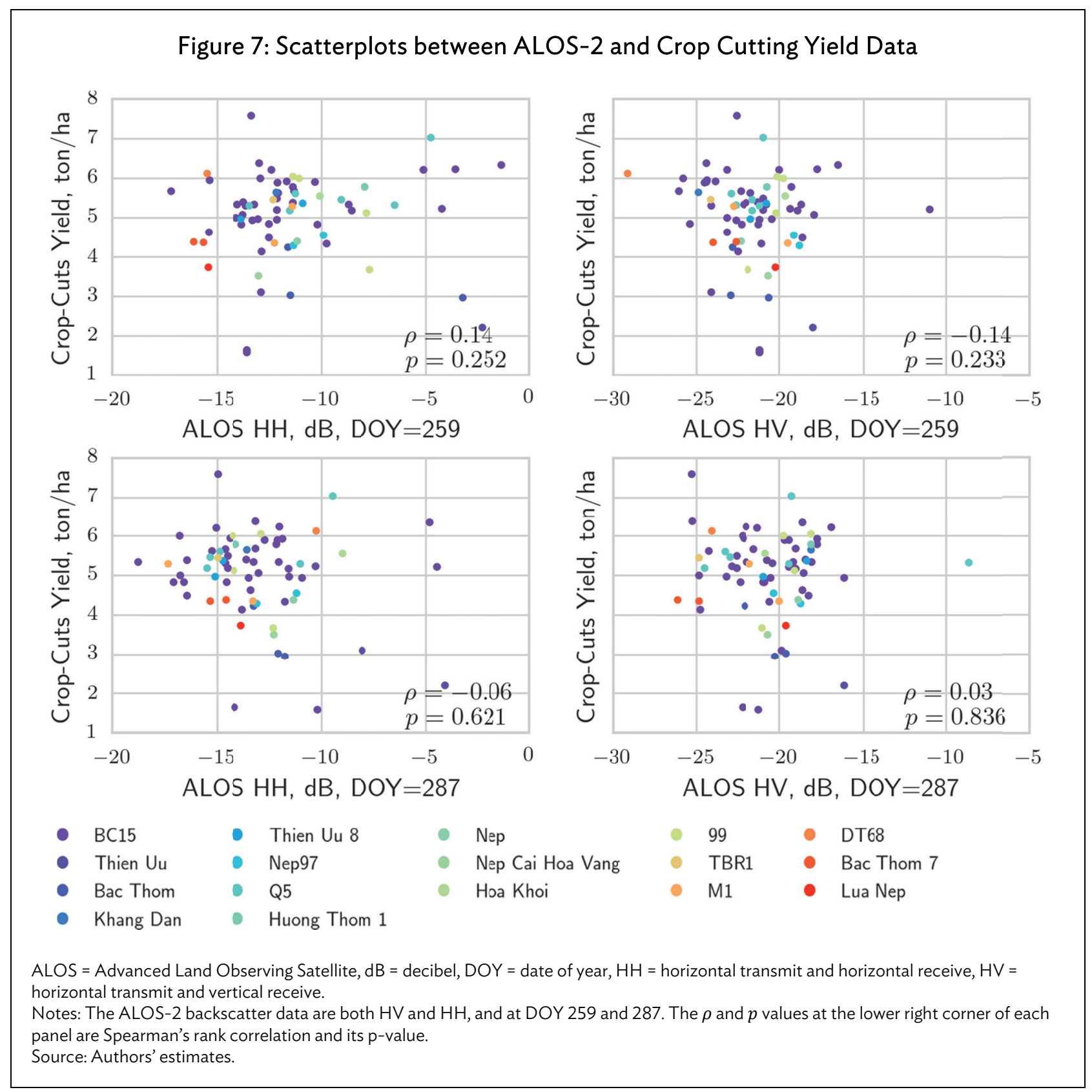


The two horizontal boxplots in Figure 9 present the statistical summaries for the two distributions of crop yield over Thai Binh. A comparison of these statistics reveals a good agreement between our model estimation and the field sampling extrapolation on the mean, $5 \mathrm{t} / \mathrm{ha}$ versus 5.39 t/ha; the median, $5.13 \mathrm{t} / \mathrm{ha}$ versus $5.27 \mathrm{t} / \mathrm{ha}$; and the lower side of the distribution with the $25 \%$ percentile of $4.64 \mathrm{t} / \mathrm{ha}$ versus $4.65 \mathrm{t} / \mathrm{ha}$. On the right tail of the probability density histogram, the fieldsampling-based distribution has more and larger values than our satellite-based one, which causes the slightly lower mean and median of crop yield in our model than the statistical extrapolation from the field samples. This difference may be caused by the saturation of NDVI at very high leaf areas and biomass of the crop vegetation. We have checked the time series of those subplots with yield larger than $6.4 \mathrm{t} / \mathrm{ha}$, i.e., the right tail of the field-sampling-based distribution. The NDVI values of these time series around the maturity phase, approximately around DOY 250, do have high values around 0.8 and show signs of plateau. However, nearly all these field subplots are nonrepresentative of the colocated Landsat pixels and thus are not sufficient to verify our hypothesis here. Further investigation with more representative field samples is needed to diagnose the saturation range of NDVI and paddy rice yield over this region.

Figure 8: Spatially Explicit Yield Map Based on Normalized Difference Vegetation Index

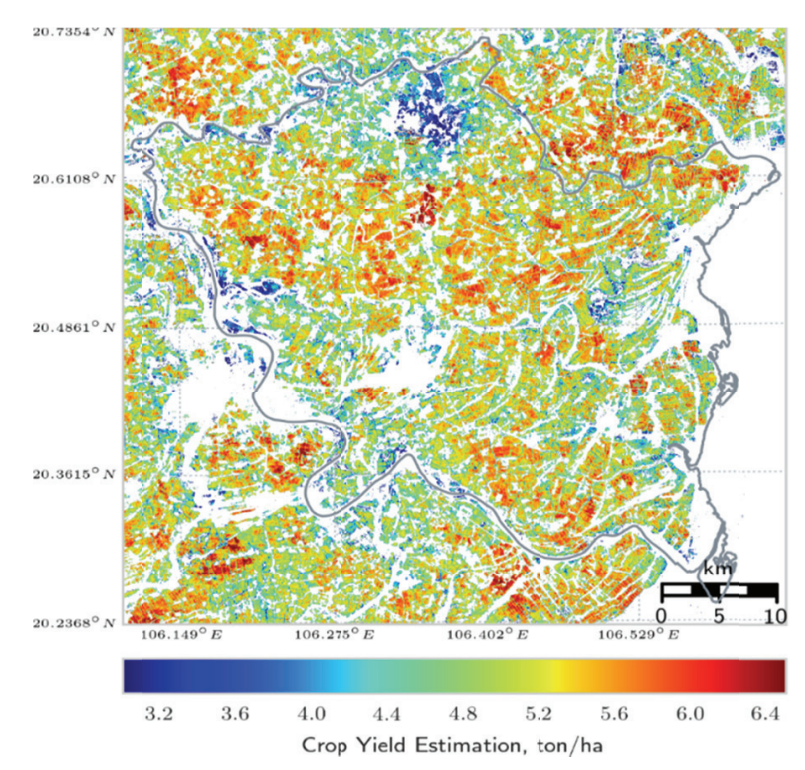

Source: Authors' estimates. 


\section{Figure 9. Probability Density Histogram of Satellite-Based and Spatially Explicit Crop Yield Estimates over Thai Binh Province}

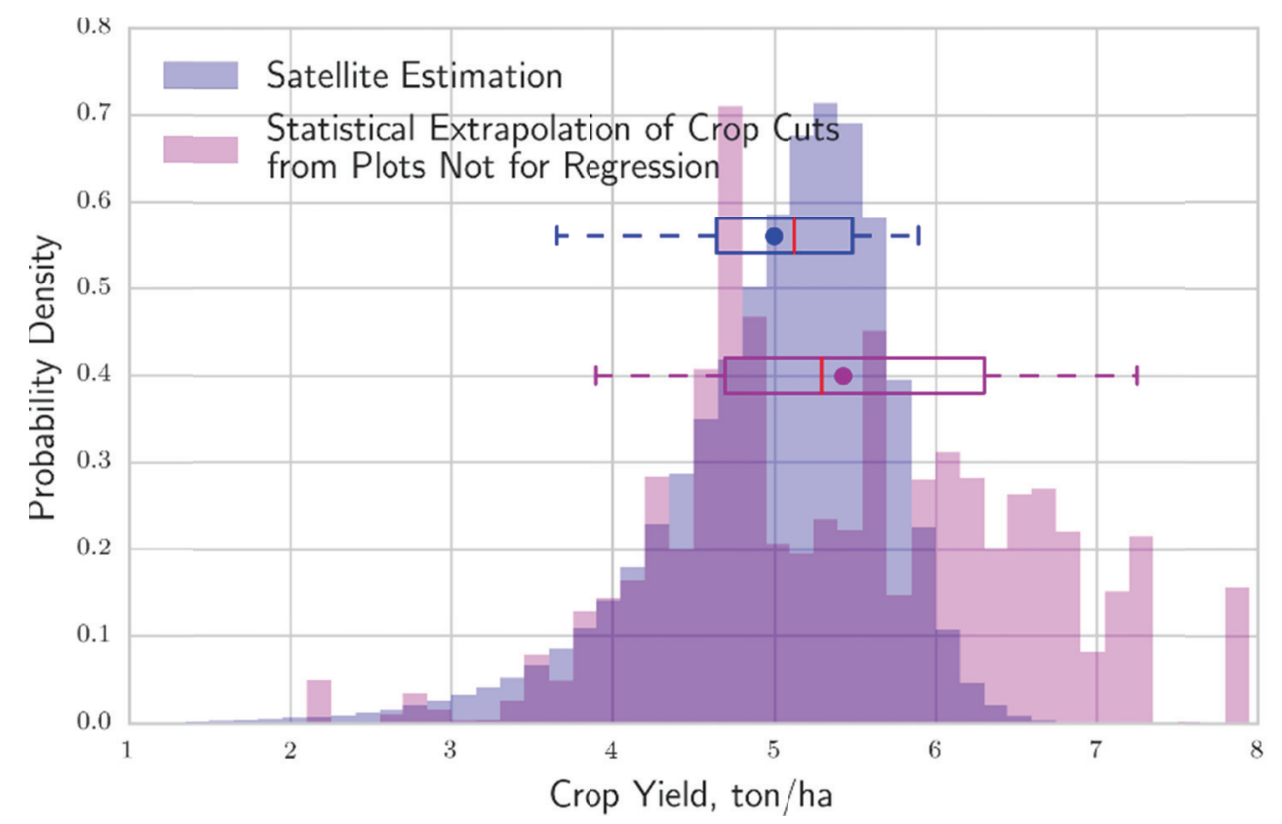

NDVI = normalized difference vegetation index.

Notes: The best yield estimation model (peak NDVI) is in blue; histogram through the statistical extrapolation of crop cutting from field samples is in purple. The two boxplots present the mean (dot), median (red vertical line), 25\% and 75\% percentiles (end of the box), as well as the $5 \%$ and $95 \%$ percentiles (end of whisks) for the satellite-based distribution in blue and the field-sampling-based distribution in purple.

Source: Authors' estimates.

\section{CONCLUSION}

In this study, multiple satellite data sources (including optical and L-band radar data) were used to map the paddy rice in Thai Binh, Viet Nam. Fused Landsat-MODIS data and crop cutting data were used for estimating field-level yield data for Thai Binh. Results show that while the Landsat-MODIS fused data does not necessarily show benefits for paddy rice mapping, it has provided great benefits for crop yield estimation. Only through the fusion data from Landsat and MODIS can we recover the peak growth trajectory of vegetation indexes. This information is the most critical input for our current algorithm. Our results also confirm the value of optical data for crop yield estimation if the cloudiness issue can be alleviated or overcome to some degree. We recognize that the current fusion approach still has room for improvement as has been reviewed by Gao et al. (2015), and as is being further improved by Zhu, Helmer, Gao, Liu, Chen, and Lefsky (2016). One possible issue here is how to best utilize the Landsat-MODIS fused data and original Landsat data. More advanced smoothing or weighted regression approaches are needed to deal with the possible discrepancy between the fused and original data. Meanwhile, emerging new datasets of surface reflectance, such as Sentinel-2 (20 m resolution, 16-day revisiting frequency) and Project for On-Board Autonomy - Vegetation (PROBA-V) from Satellite Pour l'Observation de la Terre- VEGETATION (SPOT-VGT) (100 m resolution, 16-day revisiting frequency), can further improve the temporal and spatial samplings to alleviate cloudiness 
issue in tropics. New fusion algorithms thus should consider multiple sources of data for fusion, instead of only for Landsat and MODIS.

Our study shows that L-band radar data has similar (or slightly lower) performance in paddy rice mapping as optical satellite data, but it has little contribution in crop yield estimation compared with the optical data. This result is not unexpected. L-band wavelength is too long $(\sim 23 \mathrm{~cm})$ that its backscatter can largely penetrate canopy and thus is less sensitive to the aboveground biomass (Guan et al. 2013, Waring et al. 1995). It is also worth noting that we have not tested the potentials of other radar bands (e.g., C-band, Ku-band, X-band) as data are not available. However, radar data at smaller wavelengths may show higher performance of detecting crop area and capturing crop aboveground biomass (Inoue and Sakaiya 2013). Thus, it is worth testing the radar data at smaller wavelengths for paddy rice applications.

Crop cutting data is one of the most critical inputs for this study. The field-level crop yield data made this study possible. Though the ultimate and ideal goal here is that we can use satellite data to fully substitute the labor-intensive and costly field crop cutting sampling, at the current stage of technology development, we believe that more field-level data should be collected for different regions and for multiple years. More field data especially can improve the harvest index simulation. Even when a satellite data-based algorithm of yield estimation reaches the mature stage, periodic and strategic sampling is necessary for validation. Our study also provides the implications for a better sampling protocol for field crop cutting. Specifically, the sampling design of crop cut fields should fully consider the geolocation errors of satellite data and the crop cuts' GPS sensors. In the current study, we only use the crop cutting data that locate within a Landsat pixel after accounting for the average geolocation error of Landsat data $(5.7 \mathrm{~m})$. The study has shown that adopting this filtering or not leads to large differences in the final performance of our statistical model for crop yields. Future crop cutting sampling thus should fully consider this geolocation error from both satellite images and the GPS data of the crop cutting themselves. Ideally, the region for sampling should be close to the center of a Landsat pixel. Availability of higher-spatial resolution satellite data can possibly alleviate this issue (Burke and Lobell 2017, Jain et al. 2016), though these data are usually either not freely accessible or do not cover large areas.

The current study nevertheless has a few limitations that should be improved upon in future studies. Primarily, the current project only collected crop cutting data for only one growing cycle, thus we could not test impacts of weather variability in different years on the empirical model that we built for yield estimation. Due to the relatively small area of Thai Binh, we do not expect large spatial variability in weather; moreover, we found only one weather station data for the study region from our source. Thus, we did not incorporate the weather or climate information in our current yield estimation, which are essential in capturing the yield formation during the reproductive period, and primarily related to the harvest index. At most, our current algorithm can capture the AGB's contribution to yield, but not the harvest index's contribution. Other studies on corn grown in the United States have found the harvest index contribution significant (Guan et al. 2015, Xu and Guan 2017); and that using either machine-learning-based approach (Guan et al. 2015, Xu and Guan 2017, You et al. 2017) or combining process-based crop model and satellite data (Lobell et al. 2015; Moulin, Bondeau, and Delecolle 1998) can possibly achieve the goal of modeling harvest index. Based on the above rationale, applying our derived empirical relationship beyond Thai Binh or for other years should be approached cautiously.

The ultimate goal of this study is to provide a pathway leading to an operational system for crop monitoring and yield estimation for Southeast Asian regions. We are convinced that to achieve 
this goal, optical fusion data that can provide both high temporal and spatial resolution should be paired with more weather and climate data. As this study did not model harvest index, it is essential to collect continuous climate data for the study region. Finally, a cyber-infrastructure that can allow users (primarily staff of local governments and agencies) to easily access and retrieve the information is critical for information dissemination, and should be a convenient next step. Previous efforts such as the Princeton Drought Monitor and Famine Early Warning Systems Network (FEWS-NET) have provided good examples to follow to allow low-internet bandwidth regions to use the information (Sheffield et al. 2014). How to automate satellite fusion, mapping, and yield estimation and integrate them together in a cyber-infrastructure can be a challenge and is worth future exploration.

The implications of this study extend beyond the frontiers of remote sensing. Indexes created using satellite data can be useful in designing policies to address coping mechanisms for small-scale farmers who are affected by weather-related risks. For example, insurance schemes that rely on a threshold value of NDVI or other metrics, if accurately measured, could be linked to farmer losses to design index insurance plans for poor agricultural households. The advantage of using satellite data derived indexes is that it is unbiased and minimizes transaction costs. A small but growing literature in the field of economics has been exploring the feasibility of index insurance for both crops and livestock using satellite data (Flatnes and Carter 2015, Chantarat et al. 2013, Gine et al. 2010). 


\section{APPENDIX}

Table A.1: Estimated Error Matrix for the Classification Using Landsat + ALOS-2

\begin{tabular}{lcccccccccc}
\hline Class & 1 & 2 & 3 & 4 & 5 & 6 & Total & User's & Producer's & Overall \\
\hline 1 & 0.46 & 0.01 & 0.01 & 0.02 & 0.00 & 0.01 & 0.51 & $0.91 \pm 0.02$ & $0.88 \pm 0.02$ & $0.77 \pm 0.02$ \\
2 & 0.01 & 0.01 & 0.00 & 0.01 & 0.00 & 0.00 & 0.03 & $0.45 \pm 0.10$ & $0.28 \pm 0.07$ & \\
3 & 0.05 & 0.03 & 0.17 & 0.03 & 0.00 & 0.03 & 0.31 & $0.56 \pm 0.05$ & $0.94 \pm 0.03$ & \\
4 & 0.00 & 0.00 & 0.00 & 0.11 & 0.01 & 0.00 & 0.12 & $0.87 \pm 0.05$ & $0.65 \pm 0.05$ & \\
5 & 0.00 & 0.00 & 0.00 & 0.00 & 0.01 & 0.00 & 0.01 & $0.77 \pm 0.11$ & $0.35 \pm 0.11$ & \\
6 & 0.00 & 0.00 & 0.00 & 0.00 & 0.00 & 0.01 & 0.01 & $0.41 \pm 0.10$ & $0.15 \pm 0.04$ & \\
Total & 0.52 & 0.05 & 0.18 & 0.17 & 0.02 & 0.05 & & & & \\
\hline
\end{tabular}

ALOS $=$ Advanced Land Observing Satellite, Class $1=$ Croplands, Class $2=$ Barren, Class $3=$ Built-ups, Class $4=$ Water, Class $5=$ Wetlands, Class 6 = Other vegetation

Notes: Cell entries are expressed as the estimated proportion of area. Accuracy measures are presented with a $95 \%$ confidence interval. The rows are mapped classes and the columns are reference labels.

Source: Authors' estimates.

Table A.2: Estimated Error Matrix for the Classification Using Landsat

\begin{tabular}{|c|c|c|c|c|c|c|c|c|c|c|}
\hline Class & 1 & 2 & 3 & 4 & 5 & 6 & Total & User's & Producer's & Overall \\
\hline 1 & 0.46 & 0.01 & 0.01 & 0.02 & 0.00 & 0.02 & 0.52 & $0.91 \pm 0.02$ & $0.88 \pm 0.02$ & $0.76 \pm 0.02$ \\
\hline 2 & 0.00 & 0.01 & 0.00 & 0.00 & 0.00 & 0.00 & 0.01 & $0.55 \pm 0.12$ & $0.18 \pm 0.05$ & \\
\hline 3 & 0.05 & 0.03 & 0.17 & 0.04 & 0.00 & 0.03 & 0.32 & $0.51 \pm 0.05$ & $0.94 \pm 0.03$ & \\
\hline 4 & 0.00 & 0.00 & 0.00 & 0.11 & 0.00 & 0.00 & 0.11 & $0.88 \pm 0.05$ & $0.63 \pm 0.05$ & \\
\hline 5 & 0.00 & 0.00 & 0.00 & 0.00 & 0.01 & 0.00 & 0.01 & $0.64 \pm 0.10$ & $0.42 \pm 0.13$ & \\
\hline 6 & 0.00 & 0.00 & 0.00 & 0.00 & 0.00 & 0.01 & 0.01 & $0.42 \pm 0.11$ & $0.12 \pm 0.04$ & \\
\hline Total & 0.51 & 0.05 & 0.18 & 0.17 & 0.01 & 0.06 & & & & \\
\hline
\end{tabular}

Class $1=$ Croplands, Class $2=$ Barren, Class $3=$ Built-ups, Class $4=$ Water, Class $5=$ Wetlands, Class $6=$ Other vegetation.

Notes: Cell entries are expressed as the estimated proportion of area. Accuracy measures are presented with a $95 \%$ confidence interval. The rows are mapped classes and the columns are reference labels.

Source: Authors' estimates.

Table A.3: Estimated Error Matrix for the Classification Using Fusion Normalized Difference Vegetation Index Savitzky-Golay Fit

\begin{tabular}{lcccccccccc}
\hline Class & 1 & 2 & 3 & 4 & 5 & 6 & Total & User's & Producer's & Overall \\
\hline 1 & 0.55 & 0.01 & 0.02 & 0.02 & 0.00 & 0.02 & 0.62 & $0.89 \pm 0.03$ & $0.60 \pm 0.02$ & $0.71 \pm 0.02$ \\
2 & 0.00 & 0.01 & 0.00 & 0.01 & 0.00 & 0.00 & 0.02 & $0.28 \pm 0.09$ & $0.04 \pm 0.01$ & \\
3 & 0.04 & 0.02 & 0.13 & 0.06 & 0.01 & 0.04 & 0.30 & $0.44 \pm 0.05$ & $0.16 \pm 0.02$ & \\
4 & 0.00 & 0.00 & 0.01 & 0.01 & 0.00 & 0.00 & 0.02 & $0.30 \pm 0.11$ & $0.11 \pm 0.02$ & \\
5 & 0.00 & 0.00 & 0.00 & 0.00 & 0.02 & 0.00 & 0.02 & $0.60 \pm 0.10$ & $0.03 \pm 0.01$ & \\
6 & 0.00 & 0.00 & 0.00 & 0.00 & 0.00 & 0.00 & 0.00 & $0.44 \pm 0.15$ & $0.07 \pm 0.01$ & \\
Total & 0.59 & 0.04 & 0.16 & 0.10 & 0.03 & 0.06 & & & & \\
\hline
\end{tabular}

Class $1=$ Croplands, Class $2=$ Barren, Class $3=$ Built-ups, Class $4=$ Water, Class $5=$ Wetlands, Class $6=$ Other vegetation. Notes: Cell entries are expressed as the estimated proportion of area. Accuracy measures are presented with a $95 \%$ confidence interval. The rows are mapped classes and the columns are reference labels.

Source: Authors' estimates. 
Table A.4: Estimated Error Matrix for the Classification Using ALOS-2

\begin{tabular}{lcccccccccc}
\hline Class & 1 & 2 & 3 & 4 & 5 & 6 & Total & User's & Producer's & Overall \\
\hline 1 & 0.39 & 0.01 & 0.01 & 0.04 & 0.00 & 0.01 & 0.46 & $0.83 \pm 0.03$ & $0.80 \pm 0.03$ & $0.63 \pm 0.02$ \\
2 & 0.04 & 0.01 & 0.01 & 0.02 & 0.00 & 0.01 & 0.09 & $0.08 \pm 0.04$ & $0.10 \pm 0.05$ & \\
3 & 0.05 & 0.02 & 0.14 & 0.03 & 0.02 & 0.04 & 0.30 & $0.47 \pm 0.05$ & $0.84 \pm 0.04$ & \\
4 & 0.01 & 0.02 & 0.00 & 0.08 & 0.01 & 0.00 & 0.12 & $0.70 \pm 0.07$ & $0.46 \pm 0.05$ & \\
5 & 0.00 & 0.00 & 0.01 & 0.00 & 0.01 & 0.01 & 0.03 & $0.21 \pm 0.08$ & $0.19 \pm 0.07$ & \\
6 & 0.00 & 0.00 & 0.00 & 0.00 & 0.00 & 0.00 & 0.00 & $0.08 \pm 0.09$ & $0.00 \pm 0.00$ & \\
Total & 0.49 & 0.06 & 0.17 & 0.17 & 0.04 & 0.07 & & & & \\
\hline
\end{tabular}

ALOS $=$ Advanced Land Observing Satellite, Class $1=$ Croplands, Class $2=$ Barren, Class $3=$ Built-ups, Class $4=$ Water, Class $5=$ Wetlands Class $6=$ Other vegetation .

Notes: Cell entries are expressed as the estimated proportion of area. Accuracy measures are presented with a $95 \%$ confidence interval. The rows are mapped classes and the columns are reference labels.

Source: Authors' estimates.

Table A.5: Estimated Error Matrix for the Merged Classification

\begin{tabular}{lcccccccccc}
\hline Class & 1 & 2 & 3 & 4 & 5 & 6 & Total & User's & Producer's & Overall \\
\hline 1 & 0.46 & 0.01 & 0.01 & 0.02 & 0.00 & 0.01 & 0.51 & $0.91 \pm 0.02$ & $0.88 \pm 0.02$ & $0.77 \pm 0.02$ \\
2 & 0.01 & 0.02 & 0.00 & 0.01 & 0.00 & 0.00 & 0.04 & $0.45 \pm 0.10$ & $0.30 \pm 0.07$ & \\
3 & 0.05 & 0.03 & 0.17 & 0.03 & 0.00 & 0.03 & 0.31 & $0.56 \pm 0.05$ & $0.94 \pm 0.03$ & \\
4 & 0.00 & 0.00 & 0.00 & 0.11 & 0.01 & 0.00 & 0.12 & $0.86 \pm 0.05$ & $0.65 \pm 0.05$ & \\
5 & 0.00 & 0.00 & 0.00 & 0.00 & 0.01 & 0.00 & 0.01 & $0.77 \pm 0.10$ & $0.47 \pm 0.12$ & \\
6 & 0.00 & 0.00 & 0.00 & 0.00 & 0.00 & 0.01 & 0.01 & $0.40 \pm 0.10$ & $0.14 \pm 0.04$ & \\
Total & 0.52 & 0.06 & 0.18 & 0.17 & 0.02 & 0.05 & & & & \\
\hline
\end{tabular}

Class $1=$ Croplands, Class $2=$ Barren, Class $3=$ Built-ups, Class $4=$ Water, Class $5=$ Wetlands, Class $6=$ Other vegetation.

Notes: Cell entries are expressed as the estimated proportion of area. Accuracy measures are presented with a $95 \%$ confidence interval. The rows are mapped classes and the columns are reference labels.

Source: Authors' estimates. 


\section{BIBLIOGRAPHY*}

Asian Development Bank (ADB). 2016. Results of the Methodological Studies for Agricultural and Rural Statistics. Manila.

Breiman, Leo 2001. "Random Forests." Machine Learning 45 (1): 5-32. doi:10.1088/1751$8113 / 44 / 8 / 085201$.

Burke, Marshall, and David B. Lobell. 2017. "Satellite-Based Assessment of Yield Variation and Its Determinants in Smallholder African Systems." Proceedings of the National Academy of Sciences 114 (9): 2189-94. doi:10.1073/pnas.1616919114.

Carfagna, Elisabetta, and Andrea Carfagna. 2010. "Alternative Sampling Frames and Administrative Data. What is the Best Data Source for Agricultural Statistics?" In Agricultural Survey Methods, edited by Roberto Benedetti, Marco Bee, Giuseppe Espa, Federica Piersimoni, 45-61. doi:10.1002/9780470665480.ch3.

Carletto, Calogero, Sydney Gourlay, Siobhan Murray, and Alberto Zezza. 2016. "Cheaper, Faster, and More Than Good Enough: Is GPS the New Gold Standard in Land Area Measurement?" World Bank Policy Research Working Paper. No. 7759.

Chang, Kuo-Wei, Yuan Shen, and Jeng-Chung Lo. 2005. "Predicting Rice Yield Using Canopy Reflectance Measured at Booting Stage." Agronomy Journal 97 (3): 872-78. doi:10.2134/agronj2004.0162.

Chantarat, Sommarat, Andrew G. Mude, Christopher B. Barrett, and Michael R. Carter. 2013. "Designing Index-Based Livestock Insurance for Managing Asset Risk in Northern Kenya." Journal of Risk and Insurance 80 (1): 205-37. doi:10.1111/j.1539-6975.2012.01463.x.

Chen, Chun, and Heather Mcnairn. 2006. "A Neural Network Integrated Approach for Rice Crop Monitoring." International Journal of Remote Sensing 27 (7): 1367-93. doi:10.1080/01431160500421507.

Chen, Jin, Per Jönsson, Masayuki Tamura, Zhihui Gu, Bunkei Matsushita, and Lars Eklundh. 2004. "A Simple Method for Reconstructing a High-Quality NDVI Time-Series Data Set Based on the Savitzky-Golay Filter." Remote Sensing of Environment 91 (3-4): 332-44. doi:10.1016/j.rse.2004.03.014.

Chen, Jin, Xiaolin Zhu, James E. Vogelmann, Feng Gao, and Suming Jin. 2011. "A Simple and Effective Method for Filling Gaps in Landsat ETM+ SLC-off Images." Remote Sensing of Environment 115 (4): 1053-64. doi:10.1016/j.rse.2010.12.010.

Chen, Jing, Feng Deng, and Mingzhen Chen. 2006. "Locally Adjusted Cubic-Spline Capping for Reconstructing Seasonal Trajectories of a Satellite-Derived Surface Parameter." IEEE Geoscience and Geoscience and Remote Sensing 44 (8): 2230-38.

Climate-Data.Org. https://en.climate-data.org/location/4256/.

\footnotetext{
* ADB recognizes “China” as the People's Republic of China.
} 
De Groote, Hugo, and Oumar Traoré. 2005. "The Cost of Accuracy in Crop Area Estimation." Agricultural Systems 84 (1): 21-38. http://www.sciencedirect.com/science/article/pii/ S0308521X04000976.

Desiere, Sam, and Dean Jolliffe. 2017. "Land Productivity and Plot Size - Is Measurement Error Driving the Inverse Relationship?" World Bank Policy Research Working Paper Series. 8134. http://documents.worldbank.org/curated/en/119781498874101671/pdf/WPS8134.pdf.

Dillon, Andrew, Sydney Gourlay, Kevin McGee, and Gbemisola Oseni. 2017. "Land Measurement Bias and its Empirical Implications: Evidence from a Validation Exercise." Economic Development and Cultural Change. Forthcoming.

Dong, Jinwei, and Xiangming Xiao. 2016. "Evolution of Regional to Global Paddy Rice Mapping Methods: A Review." ISPRS Journal of Photogrammetry and Remote Sensing. 119: 214-27. doi:10.1016/j.isprsjprs.2016.05.010.

European Space Agency. GlobCover. http://due.esrin.esa.int/page_globcover.php.

Fischer, Tony, Derek Byerlee, and Greg Edmeades. 2014. Crop Yields and Global Food Security: Will Yield Increase Continue to Feed the World? Australian Capital Territory: Australian Centre for International Agricultural Research.

Flatnes, Jon Einar, and Michael R. Carter. 2015. "Fail Safe Index Insurance without the Cost: A satellite Based Conditional Audit Approach." Department of Agricultural and Resource Economics Working Paper Series. University of California, Davis. https://arefiles.ucdavis.edu/uploads/filer_public/29/ec/29ecf637-f085-4c11-83be4936d2a17472/satellite_based_conditional_audit_index_insurance_150815.pdf.

Food and Agriculture Organization of the United Nations (FAO). 2016. FAOSTAT. http://www.fao.org/faostat/en/\#data/QC.

Friedl, Mark A., Douglas K. Mciver, John C. F. Hodges, Xiaoyang Y. Zhang, Douglas M. Muchoney, and Alan H. Strahler. 2002. "Global Land Cover Mapping from MODIS: Algorithms and Early Results." Remote Sensing of Environment 83 (1-2): 287-302.

Gao, Feng, Thomas Hilker, Xiaolin Zhu, Martha Anderson, Jeffrey Masek, Peijuan Wang, and Yun Yang. 2015. "Fusing Landsat and MODIS Data for Vegetation Monitoring." IEEE Geoscience and Remote Sensing Magazine 3 (3): 47-60. doi:10.1109/MGRS.2015.2434351.

Gao, Feng, Jeffrey Masek, Matt Schwaller, and Forrest Hall. 2006. "On the Blending of the Landsat and MODIS Surface Reflectance: Predicting Daily Landsat Surface Reflectance." IEEE Transactions on Geoscience and Remote Sensing. 44 (8): 2207-18. doi:10.1109/TGRS.2006.872081.

Gine, Xavier, Louis Menard, Robert Townsend, and James Vickery. 2010. "Microinsurance: A Case Study of the Indian Rainfall Index Insurance Market." World Bank Policy Research Working Paper Series. doi:https://doi.org/10.1596/1813-9450-5459.

Gitelson, Anatoly A. 2003. "Remote Estimation of Leaf Area Index and Green Leaf Biomass in Maize Canopies.” Geophysical Research Letters 30 (5): 1248. doi:10.1029/2002GL016450. 
Guan, Kaiyu, David Medvigy, Eric F. Wood, Kelly K. Caylor, Shi Li, and Su Jong Jeong. 2014. “Deriving Vegetation Phenological Time and Trajectory Information Over Africa Using SEVIRI Daily LAI." IEEE Transactions on Geoscience and Remote Sensing 52 (2): 1113-30. doi:10.1109/TGRS.2013.2247611.

Guan, Kaiyu, Adam Wolf, David Medvigy, Kelly K. Caylor, Ming Pan, and Eric F. Wood. 2013. "Seasonal Coupling of Canopy Structure and Function in African Tropical Forests and Its Environmental Controls." Ecosphere 4 (3): 1-21. http://www.esajournals.org/doi/abs/10.1890/ES12-00232.1.

Guan, Kaiyu, Yongguang Zhang, Joseph A. Berry, Joanna Joiner, Luis Guanter, Grayson Badgley, and David B. Lobell. 2015. "Improving the Monitoring of Crop Productivity Using Spaceborne Solar-Induced Fluorescence.” Global Change Biology 22 (2): 716-26. doi: 10.1111/gcb.13136.

Hansen, Matthew C., Ruth S. Defries, John R. G. Townshend, and Robert Sohlberg. 2000. "Global Land Cover Classification at $1 \mathrm{~km}$ Spatial Resolution Using a Classification Tree Approach. International Journal of Remote Sensing." 21 (6): 1331-64. doi:10.1080/014311600210209.

Huete, Alfredo, Kamel Didan, Tomoaki Miura, Edna P. Rodriguez, Xiang Gao, and Laerte Guimaraes Ferreira. 2002. "Overview of the Radiometric and Biophysical Performance of the MODIS Vegetation Indices." Remote Sensing of Environment 83 (1-2): 195-213.

Inoue, Yoshio, Takashi Kurosu, Hideo Maeno, Seiho Uratsuka, Toshiaki Kozu, Katarzyna DabrowskaZielinska, and Jiaguo Qi. 2002. "Season-Long Daily Measurements of Multifrequency (Ka, Ku, $X, C$, and L) and Full-Polarization Backscatter Signatures over Paddy Rice Field and Their Relationship with Biological Variables." Remote Sensing of Environment 81 (2-3): 194-204. doi:10.1016/S0034-4257(01)00343-1.

Inoue, Yoshio, and Eiji Sakaiya. 2013. "Relationship between X-band Backscattering Coefficients from High-Resolution Satellite SAR and Biophysical Variables in Paddy Rice." Remote Sensing Letters 4 (3): 288-95. doi:10.1080/2150704X.2012.725482.

Inoue, Yoshio, Eiji Sakaiya, and Cuizhen Wang. 2014a. "Capability of C-band Backscattering Coefficients from High-Resolution Satellite SAR Sensors to Assess Biophysical Variables in Paddy Rice." Remote Sensing of Environment 140: 257-66. doi:10.1016/j.rse.2013.09.001.

2014b. "Potential of X-band Images from High-Resolution Satellite SAR Sensors to Assess Growth and Yield in Paddy Rice." Remote Sensing 6 (7): 5995-6019. doi:10.3390/rs6075995.

International Rice Research Institute (IRRI). How to Develop a Crop Calendar. Rice Knowledge Bank. http://www.knowledgebank.irri.org/images/stories/crop-calendar-growth-dsr.jpg.

- Remote Sensing Derived Rice Maps and Related Publications. http://irri.org/ourwork/research/policy-and-markets/mapping/remote-sensing-derived-rice-maps-and-relatedpublications.

2013. Rice Almanac. Los Banos. http://books.irri.org/9789712203008_content.pdf. 
Jain, Meha, Amit K. Srivastava, Balwinder-Singh, Rajiv K. Joon, Andrew McDonald, Keitasha Royal, Madeline C. Lisaius, and David B. Lobell. 2016. "Mapping Smallholder Wheat Yields and Sowing Dates Using Micro-Satellite Data." Remote Sensing 8 (10): 860. doi:10.3390/rs8100860.

Jönsson, Per, and Lars Eklundh. 2002. "Seasonality Extraction by Function Fitting to Time-Series of Satellite Sensor Data." IEEE Transactions on Geoscience and Remote Sensing. 40 (8): 1824-32. doi:10.1109/TGRS.2002.802519.

Kuenzer, Claudia, and Kim Knauer. 2013. "Remote Sensing of Rice Crop Areas." International Journal of Remote Sensing 34 (6): 2101-39. doi:10.1080/01431161.2012.738946.

Kurosu, Takayuki, and Kaori Chiba. 1995. "Monitoring of Rice Crop Growth from Space Using the ERS1 C-band SAR." IEEE Transactions on Geoscience and Remote Sensing 33 (4): 1092-96. doi:10.1109/36.406698.

Lobell, David B., David Thau, Christopher Seifert, Eric Engle, and Bertis Britt Little. 2015. "A Scalable Satellite-Based Crop Yield Mapper." Remote Sensing of Environment 164: 324-33. doi:10.1016/j.rse.2015.04.021.

Mosleh, Mostafa Kamal, Quazi K. Hassan, and Ehsan H. Chowdhury. 2015. "Application of Remote Sensors in Mapping Rice Area and Forecasting Its Production: A Review." Sensors 15 (1): 769 91. doi:10.3390/s150100769.

Moulin, Solene, Albert Bondeau, and Richard Delecolle. 1998. "Combining Agricultural Crop Models and Satellite Observations: From Field to Regional Scales." International Journal of Remote Sensing 19 (6): 1021-37. http://www.tandfonline.com/doi/abs/10.1080/014311698215586.

NASA. Earthdata. http://reverb.echo.nasa.gov/.

NASA Landsat Science. 2017. Data: The Numbers Behind Landsat. https://landsat.gsfc.nasa.gov/data/.

Olofsson, Pontus, Giles M. Foody, Martin Herold, Stephen V. Stehman, Curtis E. Woodcock, and Michael A. Wulder. 2014. "Good Practices for Estimating Area and Assessing Accuracy of Land Change.” Remote Sensing of Environment 148: 42-57. doi:10.1016/j.rse.2014.02.015.

Olofsson, Pontus, Giles M. Foody, Stephen V. Stehman, and Curtis E. Woodcock. 2013. "Making Better Use of Accuracy Data in Land Change Studies: Estimating Accuracy and Area and Quantifying Uncertainty Using Stratified Estimation." Remote Sensing of Environment 129: 122-31. doi:10.1016/j.rse.2012.10.031.

Pal, Mahesh. 2005. "Random Forest Classifier for Remote Sensing Classification." International Journal of Remote Sensing 26 (1): 217-22. doi:10.1080/01431160412331269698.

Patel, Nikunj K., N. Ravi, Ranganath Navalgund, R. N. Dash, K. C. Das, and S. Patnaik, S. 1991. "Estimation of Rice Yield Using IRS-1A Digital Data in Coastal Tract of Orissa." International Journal of Remote Sensing 12 (11): 2259-66. doi:10.1080/01431169108955256. 
Peng, Dailiang, Jingfeng Huang, Cunjun Li, Liangyun Liu, Wenjiang Huang, Fuming Wang, and Xiaohua Yang. 2014. "Modelling Paddy Rice Yield Using MODIS Data." Agricultural and Forest Meteorology 184: 107-16. doi:10.1016/j.agrformet.2013.09.006.

Prasad, Anup K., Ramesh P. Singh, Vinod Tare, and Menas Kafatos. 2007. "Use of Vegetation Index and Meteorological Parameters for the Prediction of Crop Yield in India. International Journal of Remote Sensing." 28 (23): 5207-35. doi:10.1080/01431160601105843.

Rosenqvist, Ake, Masanobu Shimada, Shinichi Suzuki, Fumi Ohgushi, Takeo Tadono, Manabu Watanabe, and Emi Aoki. 2014. "Operational Performance of the ALOS Global Systematic Acquisition Strategy and Observation Plans for ALOS-2 PALSAR-2." Remote Sensing of Environment 155: 3-12. doi:10.1016/j.rse.2014.04.011.

Savin, Igor Y., and Vladimir A. Isaev. 2011. "Rice Yield Forecast Based on Satellite and Meteorological Data.” Russian Agricultural Sciences 36 (6): 424-27. doi:10.3103/S1068367410060108.

Sellers, Piers J., Joseph A. Berry, George James Collatz, Christopher B. Field, and Forrest G. Hall. 1992. "Canopy Reflectance, Photosynthesis, and Transpiration. III. A Reanalysis Using Improved Leaf Models and a New Canopy Integration Scheme." Remote Sensing of Environment 42 (3): 187216.

Sheffield, Justin, Eric F. Wood, Nathaniel Chaney, Kaiyu Guan, Sara Sadri, Xing Yuan, and Laban Ogallo. 2014. "A Drought Monitoring and Forecasting System for Sub-Sahara African Water Resources and Food Security." Bulletin of the American Meteorological Society 95 (6): 861-82. doi:10.1175/BAMS-D-12-00124.1.

Shen, Shuang He, Shen Bin Yang, BingBai Li, Bing Xiang Tan, Zeng Yuan Li, and Thuy Le Toan. 2009. "A Scheme for Regional Rice Yield Estimation Using ENVISAT ASAR Data." Science in China Series D: Earth Sciences 52 (8): 1183-94. doi:10.1007/s11430-009-0094-z.

Sibley, Adam M., Patricio Grassini, Nancy E. Thomas, Kenneth G. Cassman, and David B. Lobell. 2014. "Testing Remote Sensing Approaches for Assessing Yield Variability among Maize Fields." Agronomy Journal 106 (1): 24-32. doi:10.2134/agronj2013.0314.

Son, Nguyen Thanh, Chi-Farn Chen, Cheng-Ru Chen, Ly Yu Chang, Huynh-Ngoc Duc, and Lam Dao Nguyen. 2013. "Prediction of Rice Crop Yield Using MODIS EVI-LAI Data in the Mekong Delta, Viet Nam." International Journal of Remote Sensing 34 (20): 7275-92. doi:10.1080/01431161.2013.818258.

Tucker, Compton J. 1979. "Red and Photographic Infrared Linear Combinations for Monitoring Vegetation.” Remote Sensing of Environment 8 (2): 127-50.

U.S. Geological Survey (USGS). Earth Explorer. http://earthexplorer.usgs.gov.

2014. "MODIS Products Table." Land Processes Distributed Active Archive Center. https://lpdaac.usgs.gov/dataset_discovery/modis/modis_products_table/.

2016. Geometry of the Landsat Mission. https://landsat.usgs.gov/geometry. 
—. 2017a. Landsat 7 Science Data Users Handbook. https://landsat.gsfc.nasa.gov/wpcontent/uploads/2016/08/Landsat7_Handbook.pdf.

—. 2017b. Landsat 8 (L8) Data Users Handbook. https://landsat.usgs.gov/sites/default/ files/documents/Landsat8DataUsersHandbook.pdf.

Wardlow, Brian D., and Stephen L. Egbert. 2008. "Large-Area Crop Mapping Using Time-Series MODIS 250 m NDVI Data: An Assessment for the US Central Great Plains." Remote Sensing of Environment 112 (3): 1096-116. doi:10.1016/j.rse.2007.07.019.

Waring, Richard H., JoBea Way, E. Raymond Hunt Jr., Leslie Morrissey, K. Jon Ranson, John F. Weishampel, and Steven E. Franklin. 1995. "Imaging Radar for Ecosystem Studies.” BioScience 45 (10): 715-23.

Whitcraft, Alyssa K., Inbal Becker-Reshef, and Christopher O. Justice. 2015. "A Framework for Defining Spatially Explicit Earth Observation Requirements for a Global Agricultural Monitoring Initiative (GEOGLAM).” Remote Sensing 7 (2): 1461-81. doi:10.3390/rs70201461.

World Bank. 2016. World Bank Global Consumption Database. http://datatopics.worldbank.org/ consumption/.

Xiao, Xiangming, Stephen Boles, Steve Frolking, Changsheng Li, Jagadeesh Y. Babu, William Salas, and Berrien Moore III. 2006. "Mapping Paddy Rice Agriculture in South and Southeast Asia Using Multi-Temporal MODIS Images." Remote Sensing of Environment 100 (1): 95-113. doi:10.1016/j.rse.2005.10.004.

Xiao, Xiangming, Stephen Boles, Jiyuan Liu, Dafang Zhuang, Steve Frolking, Changsheng Li, and Berrien Moore III. 2005. "Mapping Paddy Rice Agriculture in Southern China Using MultiTemporal MODIS Images." Remote Sensing of Environment 95 (4): 480-92. doi:10.1016/j.rse.2004.12.009.

Xu, Xiangtao, and Kaiyu Guan. 2017. Temporally and Spatially Varying Responses of Rainfed Crop Yield to Climate and Extreme Events in the U.S. Environmental Research Letters. Under review.

You, Jiaxuan, Xiaocheng Li, Melvin Low, David B. Lobell, and Stefano Ermon. 2017. Deep Gaussian Process for Crop Yield Prediction Based on Remote Sensing Data. CA, USA: Department of Computer Science, Stanford University. https://cs.stanford.edu/ ermon/group/website/ papers/jiaxuan_AAAI17.pdf.

Zhang, Xiaoyang, Mark A. Friedl, Crystal B. Schaaf, Alan H. Strahler, John C. F. Hodges, Feng Gao, and Alfredo Huete. 2003. "Monitoring Vegetation Phenology Using MODIS." Remote Sensing of Environment 84 (3): 471-75.

Zhu, Xiaolin, Eileen H. Helmer, Feng Gao, Desheng Liu, Jin Chen, and Michael A. Lefsky. 2016. "A Flexible Spatiotemporal Method for Fusing Satellite Images with Different Resolutions." Remote Sensing of Environment 172: 165-77. doi:10.1016/j.rse.2015.11.016. 
Zhu, Xiaolin, Desheng Liu, and Jin Chen. 2012. "A New Geostatistical Approach for Filling Gaps in Landsat ETM+ SLC-off Images." Remote Sensing of Environment 124: 49-60. doi:10.1016/j.rse.2012.04.019.

Zhu, Zhe, Yingchun Fu, Curtis E. Woodcock, Pontus Olofsson, James E. Vogelmann, Christopher Holden, and Yang Yu. 2016. "Including Land Cover Change in Analysis of Greenness Trends Using All Available Landsat 5, 7, and 8 Images: A Case Study from Guangzhou, China (20002014)." Remote Sensing of Environment 185: 243-57. doi:10.1016/j.rse.2016.03.036.

Zhu, Zhe, Curtis E. Woodcock, John Rogan, and Josef Kellndorfer. 2012. "Assessment of Spectral, Polarimetric, Temporal, and Spatial Dimensions for Urban and Peri-Urban Land Cover Classification using Landsat and SAR Data." Remote Sensing of Environment 117: 72-82. 


\section{Measuring Rice Yield from Space: The Case of Thai Binh Province, Viet Nam}

Traditional methods for estimating rice yield rely on field data, which are time-consuming and expensive to collect. Significant cloud coverage in Southeast Asia limits the availability of cloud-free satellite images to serve as an alternative to field data. This paper presents an innovative data fusion technique which combines two freely available sources of satellite data for Thai Binh, Viet Nam. Our results show that data fusion increases the spatial and temporal availability of satellite data and allows for estimating the best empirical relationship between satellite derived yield indexes and field-based yield data.

\section{About the Asian Development Bank}

ADB's vision is an Asia and Pacific region free of poverty. Its mission is to help its developing member countries reduce poverty and improve the quality of life of their people. Despite the region's many successes, it remains home to a large share of the world's poor. ADB is committed to reducing poverty through inclusive economic growth, environmentally sustainable growth, and regional integration.

Based in Manila, ADB is owned by 67 members, including 48 from the region. Its main instruments for helping its developing member countries are policy dialogue, loans, equity investments, guarantees, grants, and technical assistance. 